\title{
Cerebrospinal fluid and venous biomarkers of shunt-responsive idiopathic normal pressure hydrocephalus: a systematic review and meta-analysis
}

\author{
Santhosh G. Thavarajasingam ${ }^{1} \cdot$ Mahmoud El-Khatib $^{1} \cdot$ Kalyan V. Vemulapalli $^{1} \cdot$ Hector A. Sinzinkayo Iradukunda ${ }^{1}$. \\ Joshua Laleye ${ }^{1} \cdot$ Salvatore Russo $^{2}$. Christian Eichhorn ${ }^{3} \cdot$ Per K. Eide E,5 $^{4}$
}

Received: 6 January 2022 / Accepted: 10 February 2022 / Published online: 1 March 2022

(c) The Author(s) 2022

\begin{abstract}
Background Idiopathic normal pressure hydrocephalus (iNPH) is a neurodegenerative disease and dementia subtype involving disturbed cerebrospinal fluid (CSF) homeostasis. Patients with iNPH may improve clinically following CSF diversion through shunt surgery, but it remains a challenge to predict which patients respond to shunting. It has been proposed that CSF and blood biomarkers may be used to predict shunt response in iNPH.

Objective To conduct a systematic review and meta-analysis to identify which CSF and venous biomarkers predict shuntresponsive iNPH most accurately.

Methods Original studies that investigate the use of CSF and venous biomarkers to predict shunt response were searched using the following databases: Embase, MEDLINE, Scopus, PubMed, Google Scholar, and JSTOR. Included studies were assessed using the ROBINS-I tool, and eligible studies were evaluated utilising univariate meta-analyses.

Results The study included 13 studies; seven addressed lumbar CSF levels of amyloid- $\beta$ 1-42, nine studies CSF levels of Total-Tau, six studies CSF levels of Phosphorylated-Tau, and seven studies miscellaneous biomarkers, proteomics, and genotyping. A meta-analysis of six eligible studies conducted for amyloid- $\beta \quad 1-42$, Total-Tau, and Phosphorylated-Tau demonstrated significantly increased lumbar CSF Phosphorylated-Tau $(-0.55 \mathrm{SMD}, p=0.04)$ and Total-Tau $(-0.50 \mathrm{SMD}$, $p=0.02)$ in shunt-non-responsive iNPH, though no differences were seen between shunt responders and non-responders for amyloid- $\beta$ 1-42 $(-0.26$ SMD, $p=0.55)$ or the other included biomarkers.

Conclusion This meta-analysis found that lumbar CSF levels of Phosphorylated-Tau and Total-Tau are significantly increased in shunt non-responsive iNPH compared to shunt-responsive iNPH. The other biomarkers, including amyloid- $\beta$ 1-42, did not significantly differentiate shunt-responsive from shunt-non-responsive iNPH. More studies on the Tau proteins examining sensitivity and specificity at different cut-off levels are needed for a robust analysis of the diagnostic efficiency of the Tau proteins.
\end{abstract}

Keywords Diagnosis $\cdot$ Normal pressure hydrocephalus $\cdot$ Predict $\cdot$ Shunt response $\cdot$ iNPH $\cdot$ Biomarker $\cdot$ Tau

\section{Abbreviations \\ 5-HIAA alb-GP \\ 5-Hydroxy-indoleacetic acid \\ Alpha 1 beta glycoprotein}

This article is part of the Topical Collection on CSF Circulation

Santhosh G. Thavarajasingam

sgt16@ic.ac.uk

1 Faculty of Medicine, Imperial College London, London, UK

2 Department of Neurosurgery, Imperial College Healthcare NHS Trust, London, UK

3 Division of Internal Medicine, University Hospital Basel, Basel, Switzerland
4 Department of Neurosurgery, Oslo University Hospital, Rikshospitalet, Oslo, Norway

5 Faculty of Medicine, Institute of Clinical Medicine, University of Oslo, Oslo, Norway 


\begin{tabular}{|c|c|}
\hline a2-HS-GP & $\begin{array}{l}\text { Alpha } 2 \text { Heremans-Schmid } \\
\text { glycoprotein }\end{array}$ \\
\hline $\mathrm{AD}$ & Alzheimer's disease \\
\hline $\mathrm{a} \beta \mathrm{O} 10-20$ & $\begin{array}{l}\text { Amyloid- } \beta \text { oligomers, consisting of } \\
10-20 \text { monomers }\end{array}$ \\
\hline Amyloid- $\beta$ 1-42 & Amyloid beta 1.42 \\
\hline Apo E & Apolipoprotein E \\
\hline Apo $\mathrm{J}$ & Apolipoprotein J \\
\hline AUROC & $\begin{array}{l}\text { Area under the receiving operating } \\
\text { characteristic }\end{array}$ \\
\hline BGS & Black Grading Scale \\
\hline CSF & Cerebrospinal fluid \\
\hline ELD & Extended lumbar drainage \\
\hline FU & Follow-up \\
\hline GABA & Gamma amino butyric acid \\
\hline GFAP & Glial fibrillary acid protein \\
\hline HMPG & 4-Hydroxy-3-Methoxyphenylglycol \\
\hline HVA & Homovanillic acid \\
\hline ICPM & Intracranial pressure monitoring \\
\hline iNPH & $\begin{array}{l}\text { Idiopathic normal pressure } \\
\text { hydrocephalus }\end{array}$ \\
\hline LP & Lumbar puncture \\
\hline LRG & Leucine-rich alpha-2 glycoprotein \\
\hline LTFU & Lost-to-follow-up \\
\hline MALDI TOF MS & $\begin{array}{l}\text { 2D-Gel electrophoresis and matrix- } \\
\text { assisted laser desorption/ionisation } \\
\text { and time of flight mass spectrometry } \\
\text { desorption/ionisation and time of } \\
\text { flight mass spectrometry }\end{array}$ \\
\hline MMP & Matrix metalloproteinases \\
\hline MMSE & Mini-mental state examination \\
\hline MRS & Modified Rankin Scale \\
\hline NFL & Neurofilament triplet protein \\
\hline NPY & Neuropeptide Y \\
\hline OCEBM & $\begin{array}{l}\text { Oxford Centre of Evidence Based } \\
\text { Medicine Levels of Evidence }\end{array}$ \\
\hline PRISMA & $\begin{array}{l}\text { Preferred Reporting Items for System- } \\
\text { atic Reviews and Meta-Analyses }\end{array}$ \\
\hline P-Tau & Phosphorylated Tau protein \\
\hline ROBINS-I & $\begin{array}{l}\text { Risk Of Bias in Non-randomised } \\
\text { Studies of Interventions }\end{array}$ \\
\hline ROC & $\begin{array}{l}\text { Receiver operating characteristic } \\
\text { (ROC) }\end{array}$ \\
\hline SMD & Standardised mean difference \\
\hline S-R & Shunt responder \\
\hline S-NR & Shunt non-responder \\
\hline TIMP-1 & $\begin{array}{l}\text { Tissue inhibitor matrix metallopro- } \\
\text { teinase } 1\end{array}$ \\
\hline TT & Tap test \\
\hline T-Tau & Total Tau protein \\
\hline VIP & Vasoactive intestinal peptide \\
\hline
\end{tabular}

\section{Introduction}

Idiopathic normal pressure hydrocephalus (iNPH) is a neurodegenerative disease and subtype of dementia incorporating disturbed cerebrospinal fluid (CSF) homeostasis, first described in 1965 [2]. The clinical symptoms include gait ataxia, cognitive decline (dementia), urinary incontinence, and apathy [67] that may improve following CSF diversion (shunt) surgery. It remains an obstacle, however, that even though affected individuals fulfil the diagnostic criteria of probable iNPH according to the American-European [62] or Japanese $[35,56]$ guidelines, likely response to shunt surgery cannot be predicted from fulfilling the current diagnostic criteria. Therefore, the guidelines also differentiate between shunt-responsive and shunt-non-responsive iNPH. As a supplement to the guidelines, various predictors of shunt-responsive iNPH have been introduced [49]. The most common supplemental tests include imaging biomarkers of ventriculomegaly and CSF disturbance $[3,23,75]$ biomarkers of CSF pressure dynamics (infusion tests and intracranial pressure (ICP) measures) $[16,24,77]$ and clinical assessment following small (tap test) [77] or large (extended lumbar drain) [50] volume CSF diversion. Since the sole treatment option, shunt surgery, requires surgical intervention in the brain of affected individuals with a definite risk of severe complications $[27,47,55,62]$, there is a great need for identifying biomarkers of shunt-responsive iNPH $[56,71]$. In addition, the occurrence of iNPH may be higher than previously assumed and may even affect several million people in Europe alone [5, 10, 36]. These figures also call for less invasive predictors of shunt-responsive iNPH.

There is a close overlap between iNPH and Alzheimer's disease (AD) as both conditions present with abnormal deposition in the brain of toxic by-products of cerebral metabolism, such as amyloid-beta 1-42 (amyloid- $\beta$ 1-42) and Tau [42]. Evidence from brain tissue examination even suggests that iNPH may be a model disease of Alzheimer's disease [44]. Others have shown that comorbid Alzheimer's disease is a strong predictor of shunt non-responsive iNPH $[7,8,28,29]$. More recently, it was suggested that a final common pathway to dementia disease may be the pathological cerebral aggregation of toxic by-products of brain metabolism caused by impaired cerebral clearance of these waste products, e.g., deposition of amyloid- $\beta$ 1-42 and Tau in Alzheimer's disease and $\alpha$-synuclein in Parkinson's disease [57]. Due to the close association between iNPH and other dementia diseases such as Alzheimer's disease and Parkinson's disease, levels of biomarkers of neurodegeneration in CSF or blood could be used to differentiate shuntresponsive from shunt-non-responsive iNPH. Accordingly, the biomarkers Total-Tau (T-Tau) and amyloid- $\beta$ 1-42 were previously hypothesised to aid in differentiating between 
Alzheimer's disease and iNPH [37, 38]. Other biomarkers such as Phosphorylated-Tau (P-Tau) [12], interleukins [45], and neurofilament triplet protein (NFL) $[4,73]$ were suggested to participate in the evolvement of hydrocephalus and other neurological conditions. In line with this, the most recent guidelines for the management of iNPH patients recommend CSF assessment for all suspected iNPH patients [56].

To this end, there have been three systematic reviews investigating the role of biomarkers in iNPH diagnosis. Two studies compared biomarkers in iNPH to healthy controls, Alzheimer's disease, and other forms of dementia [12, 48]; however, their definition of iNPH diagnosis did not require shunt response. Furthermore, these papers did not answer the most valuable question of whether a biomarker can reliably indicate if a patient will benefit from shunt insertion. Depending on the patient selection process, the reported proportion of patients responding to shunt surgery varies between 59 and 90\% [24, 31, 72]. Moreover, shunt surgery in iNPH carries a significant risk of complications [41, 55, 72]. To avoid shunt surgery in iNPH patients who most likely do not respond, identifying biomarkers of shunt-responsive iNPH is highly warranted. One systematic review from 2017 [59] did explore this topic but did not include a meta-analysis. Furthermore, even the recommendations made in the latest guidelines on CSF biomarker analysis in iNPH management [56] are limited in their internal validity, as they drew their conclusion based on purely qualitative collation of different studies, without a single meta-analysis. Given these strong limitations in the current literature, our review aims to qualitatively and quantitatively evaluate the diagnostic effectiveness of the most important current biomarkers in identifying shunt-responsive iNPH, incorporating the latest primary research.

\section{Methods}

\section{Literature search}

This systematic review was conducted following the Cochrane Collaboration guidelines [13] and Preferred Reporting Items for Systematic Reviews and Meta-Analyses (PRISMA) [53]. Supplemental Table 1 shows the completed PRISMA Checklist. A comprehensive search of MEDLINE and Embase was conducted from January 1965 to November 2021 performed to answer the following research question: "Which cerebrospinal and venous biomarkers predict shuntresponsive iNPH?". Normal-pressure hydrocephalus was first described in 1965 [2]. The search terms are presented in Supplementary Table 2. Additional original articles were identified by manual searching in Scopus, PubMed, Google
Scholar, and JSTOR using the search strings as specified in Supplementary Table 2.

\section{Study inclusion and exclusion criteria}

Our inclusion criteria were the following: adult iNPH patients, radiological confirmation of hydrocephalus, one or more clinical features of iNPH, use of cerebrospinal fluid shunt, objective system of functional grading of patients preoperatively, and a minimum of 3 months post-operatively. Biochemical testing was done to predict shunt response. The exclusion criteria were the following: studies that looked solely at invasive cortical biopsies, as cortical biopsy was deemed to be not significantly less invasive than shunt insertion. In the first abstract search, all original articles in the English language that reported on iNPH diagnosis were included. Subsequently, from this preliminary list, only studies reporting on the use of biochemical markers for the prediction of shunt response in iNPH management, as well as those fulfilling our inclusion criteria, were included.

\section{Eligibility assessment, data extraction, and quality assessment}

All included papers were assessed for eligibility independently by two independent reviewers. Any disagreements were resolved by consensus after discussion with a third and fourth reviewer. All relevant data were extracted using the Covidence data collection tool [14]. Relevant data included author names, publication dates, study type, shunted patients, study methodology (sample type, assessments, follow-up), criteria for shunt response, main reported outcomes (differences in biomarker levels in standard mean difference between shunt responders and shunt non-responders, area under curve, sensitivity, and specificity of the biomarker for predicting shunt-responsive iNPH), complications and dropout rates, funding declarations, as well as conflicts of interests. No assumptions were made regarding any studies' content. All articles were critically appraised using the ROBINS-I tool by two independent reviewers, and a consensus was reached by discussion with a third reviewer [69]. Furthermore, the level of evidence for each included article was scored using the Oxford Centre of Evidence-Based Medicine (OCEBM) Levels of Evidence Table [34].

\section{Statistical analysis}

An Egger's regression and asymmetry test [13] were used to assess publication bias $(p<0.05 \%=$ significant $)$. Data preparation, statistical analysis, and forest plot synthesis were carried out by utilising meta package [64] with the R software (version 4.0.4) [61]. The data sheets and $\mathrm{R}$ code are shown in Supplementary Tables 3-6. Stata (Release 17) was utilised 
to create an albatross plot [68]. A random-effects subgroup meta-analysis was conducted for each CSF biomarker that had three or more studies discussing its use. Studies must have included the following information: sample size for shunt-responsive and non-shunt-responsive group and for each biomarker, the mean, standard deviation, and $p$-value comparing the two groups. If only two studies discussed a biomarker, then the biomarker was included in the albatross plot but not in the meta-analysis. If only one study discussed a biomarker, then the biomarker was excluded from both the meta-analysis and albatross plot. Shunt responder biochemical marker data was used as the dependent variable, to which the shunt non-responder biochemical marker data was the independent variable. The inverse variance method was used for pooling effect sizes [26]. The Hartung-Knapp method was used to adjust test statistics and confidence intervals [30]. Cohen's d was utilised to estimate the standardised mean difference (SMD). The restricted maximum-likelihood estimator was used to analyse variance between studies. The $t$-test was used to calculate the overall statistical result of each meta-analysis with the associated $p$-value. Heterogeneity was estimated using the chi-squared statistic $\left(I^{2}\right)$ with the associated $p$-value. A statistical significance was assumed for $p<0.05$. A sensitivity analysis was performed in two steps. Firstly, if included studies for each biomarker metaanalysis were rated at "serious" or "critical" overall risk of bias according to ROBINS-I tool, an additional subgroup random-effects meta-analysis without these studies was performed by utilising meta package [64] with the R software (version 4.0.4) [61]. Secondly, a multi-variate mixed-effects meta-regression model was built and calculated by utilising meta package [64] with the R software (version 4.0.4) [61]. The following regression equation was employed:

$\widehat{\theta}_{k}=\theta+\beta_{1} x_{k}+\epsilon_{k}+\zeta_{k}$

Reading the equation left to right, $\widehat{\theta}_{k}$ denotes the observed effect size of each study $(k)$ and acts as the dependent variable. $\theta$ denotes the $y$-axis intercept, and $\beta_{1} x_{k}$ is the independent variable, an arm-level covariate vector. The variables $\epsilon_{k}$ and $\zeta_{k}$ denote two independent error variables. $\zeta_{k}$ explains that even the measured true effect size of each study is merely sampled from an overarching effect size distribution, which implies that heterogeneity variance exists between studies. The error term $\epsilon_{k}$ describes the underlying independent sampling error which causes the effect size of a study to deviate from the true effect size. In this study, the following explanatory variables model was chosen to explain and represent the error term $\epsilon_{k}$ :

$\epsilon_{k}=\left(\beta_{2_{\text {age }}}+\beta_{3_{\text {females }}}+\beta_{4_{\text {sample }}}+\beta_{5_{\text {date }}}+\beta_{6_{\text {strm }}}+\beta_{7_{\text {neuro }}}+\beta_{8_{\text {dropout }}}\right) x_{k}$
The error term $\epsilon_{k}$ is hypothesised to be influenced by age of the patient population $\left(\beta_{2_{\text {age }}}\right)$, the proportion of females in the percentage of overall population sample $\left(\beta_{3_{\text {females }}}\right)$, the sample size (number of shunt responders and shunt nonresponders $)\left(\beta_{3_{\text {sample }}}\right)$, the date of publication $\left(\beta_{4_{\text {date }}}\right)$, the method of shunt response measurement $\left(\beta_{5_{s t m}}\right)$, and the dropout rate $\left(\beta_{9_{\text {dropout }}}\right)$ for each study $\left(x_{k}\right)$. The different explanatory variables were calculated singularly as sole covariates in separate meta-regressions, and if significant coefficients were yielded, further regression analyses were performed by adding additional covariates to the sole covariate to assess if significance was retained. Furthermore, a bubble plot was created using the R software (version 4.0.4) [61] to visualise the meta-regression of significant covariates. Finally, an additional meta-analysis was subsequently performed by removing the studies that caused the significant covariates. The significant studies were identified by examining the bubble plots for outliers.

\section{Results}

The literature search retrieved a total of 1,554 papers for abstract screening, of which 289 papers underwent fulltext review and 13 studies were included (Fig. 1) [1, 4, 15, $33,39,51,52,58,60,65,70,73,74]$. The pooled sample size of these 13 studies was $n=776$ shunted patients. The ROBINS-I tool scored eight of the included studies at low risk of bias overall, three studies at moderate risk, one study at serious risk, and one study at critical risk (Fig. 2). The Oxford Centre for Evidence-Based Medicine (OCEBM) analysis [34] scored 12 studies at "Level 3" [1, 4, 15, 33, $39,51,52,58,65,70,73,74]$ and one study [60] at "Level 2". No clear funnel plot asymmetry was detected (Fig. 3A), and similarly Egger's test yielded no significant publication bias ( $p=0.0989)$ (Fig. 3B). Thirteen studies investigated in total 21 biomarkers (Table 1, Table 2, Table 3), of which 18 were CSF biomarkers (Amyloid- $\beta$ 1-42, T-Tau, P-Tau, NFL, sulfatide, albumin, vasoactive intestinal peptide (VIP), leucine-rich alpha-2 glycoprotein, and extracellular matrix proteins) and one was a genotyping biomarker (distribution of the apolipoprotein E genotype). Furthermore, two ratios of CSF biomarkers were examined for their use as biomarkers (T-Tau/amyloid- $\beta$ 1-42 and P-Tau/amyloid- $\beta$ 1-42) to predict shunt response in iNPH patients.

\section{Amyloid- $\beta$ 1-42}

Seven studies investigated lumbar CSF amyloid- $\beta$ 1-42 as a prognostic biomarker in predicting shunt response (Table 1). Of these, Tarnaris et al. (2011) [70] reported higher preoperative amyloid- $\beta$ 1-42 lumbar CSF levels in shunt 
Fig. 1 Preferred Reporting Items for Systematic Reviews and Meta-Analyses (PRISMA) flowchart outlining the study selection process

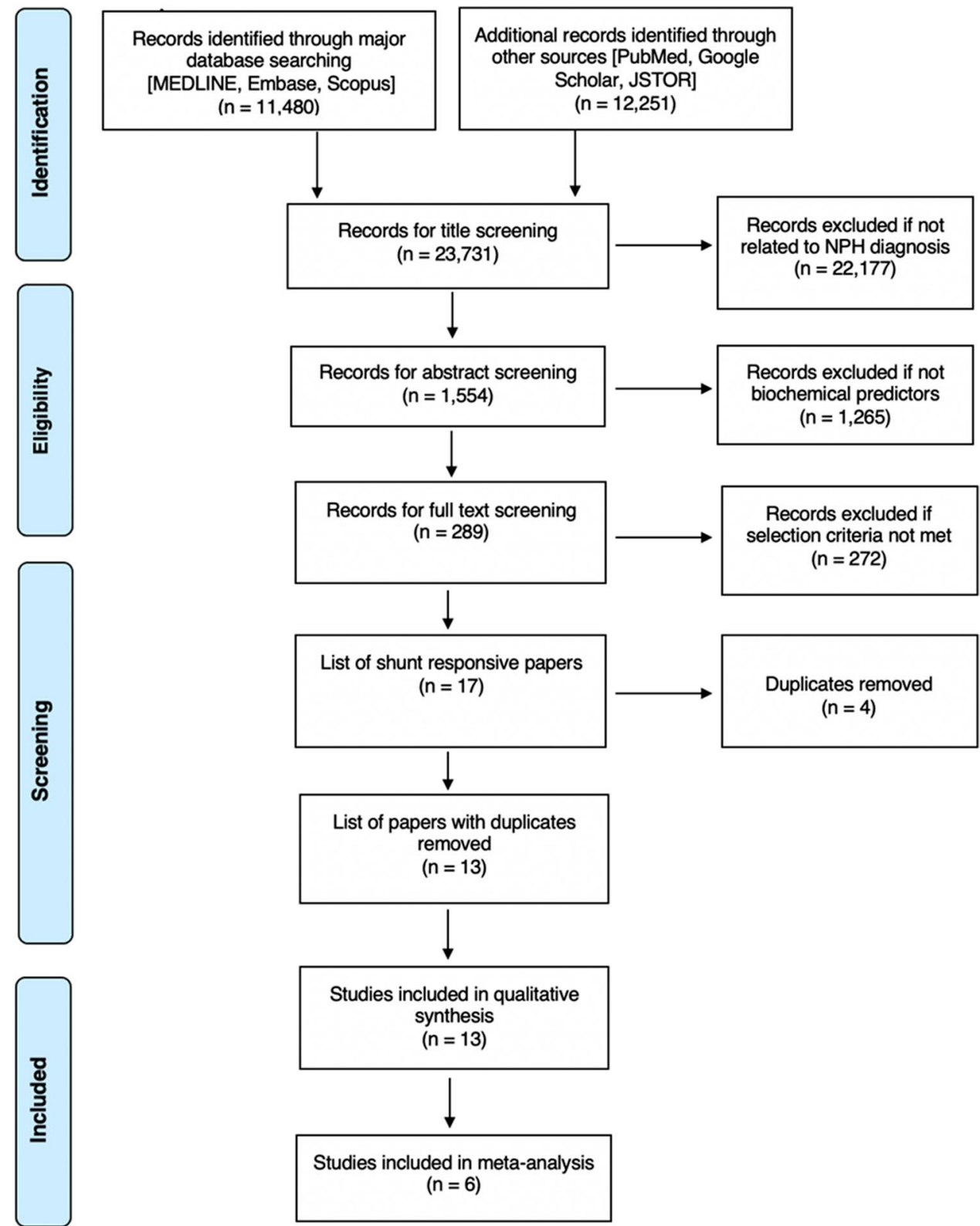

non-responders $(p=0.011)$. In contrast, the remainder of the studies reported no significant difference in the CSF levels of amyloid- $\beta$ 1-42 between shunt responders and shunt non-responders [1, 4, 15, 33, 51, 74]. Craven et al. (2017) [15] explored the pre-operative level of amyloid- $\beta$ 1-42 in ventricular CSF in shunt responders and shunt non-responders, which was insignificant $(p=0.51)$. At a cut-off level $500 \mathrm{ng} / \mathrm{l}$, Craven et al. (2017) [15] reported a sensitivity of $79 \%$ and a specificity of $25 \%$, but their area under the receiving operating characteristic (AUROC) analysis was insignificant at 0.5. However, Migliorati et al. (2020) [51] performed a univariate logistic regression showing that lumbar CSF levels of amyloid- $\beta$ 1-42 exceeding $731.7 \mathrm{ng} / \mathrm{l}$ were significantly associated with poor shunt response $(p=0.038)$. The best cut-off identified was, after receiver operating characteristic (ROC) analysis, set at $731.7 \mathrm{ng} / \mathrm{L}$ for lumbar CSF amyloid- $\beta$ 1-42 levels, yielding a sensitivity of $72.7 \%$ and a specificity of $79.3 \%$ for predicting shunt response.

\section{Total-Tau}

Nine studies investigated the use of T-Tau to predict shunt response (Table 2) [1, 4, 15, 33, 51, 58, 70, 73, 74]. Of these, three studies reported that T-Tau was a prognostic biomarker that displayed a significant difference between shunt-responsive and non-responsive patients when comparing the pre-operative lumbar levels of T-Tau. Craven et al. (2017) [15] and Migliorati et al. (2020) [51] 
Fig. 2 A risk of bias summary plot for non-randomised studies with bar chart of the distribution of risk-of-bias judgements for all included studies $(n=13)[1$, $4,15,33,39,51,52,58,60,65$, $70,73,74]$ across the domains of the ROBINS-I tool, shown in percentages (\%) is shown. In the bottom, an overall risk of bias, which represents the collated risk-of-bias judgements for all domains, is depicted

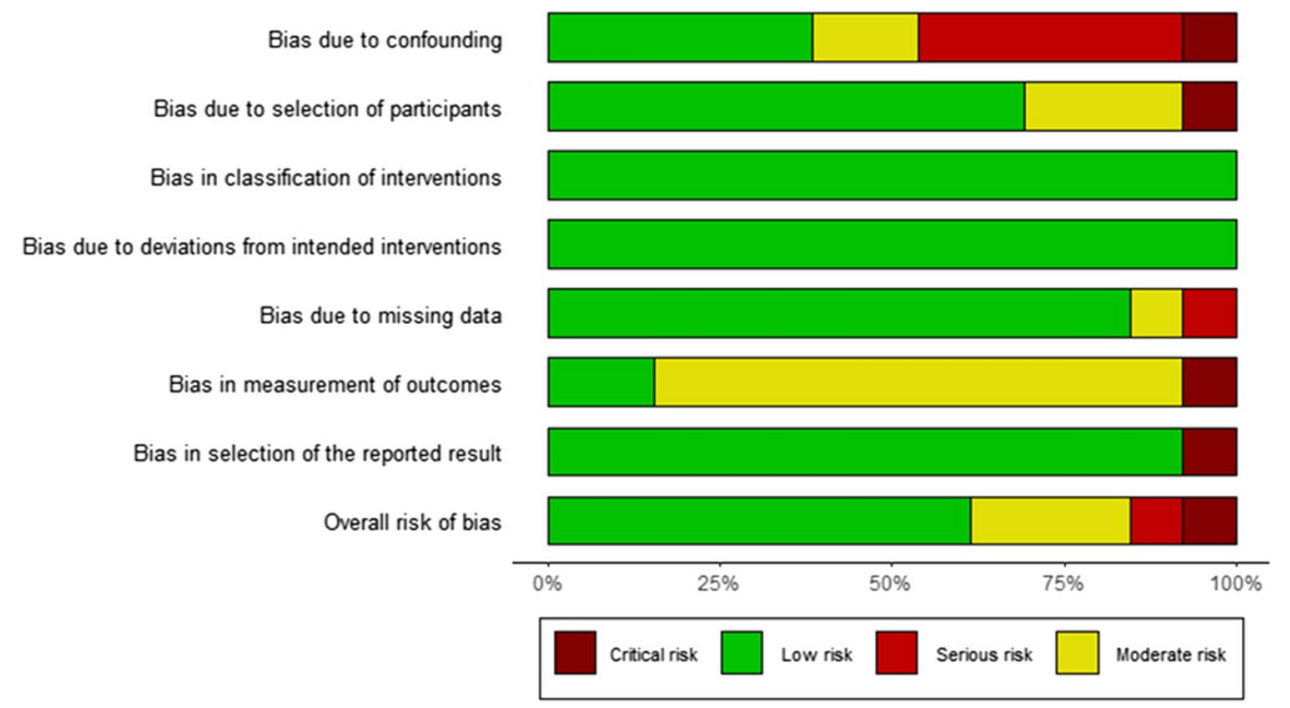

Bias due to confounding

Bias due to selection of participants

Bias in classification of interventions

Bias due to missing data

Bias in measurement of outcomes

ias in selection of the reported result

B

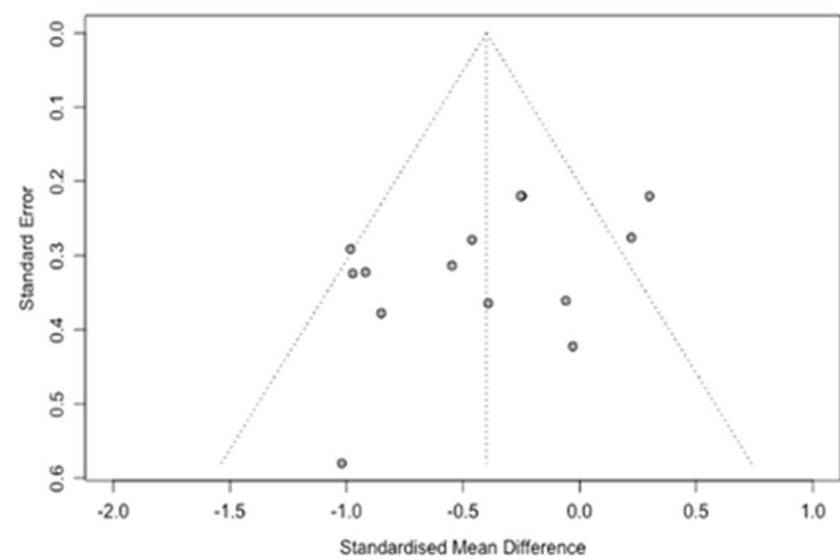

Fig. 3 A A funnel plot is shown, which plots every study included in the meta-analysis $(n=14 ; 6$ original studies but used and counted multiple times due to reporting on multiple biomarkers) $[4,33,51$, $70,73,74]$, particularly their observed effect sizes (standard mean difference) on the $\mathrm{x}$-axis against a measure of their standard error on the y-axis. B An Egger's asymmetry test funnel plot of all data points included in the meta-analysis $(n=14 ; 6$ original studies but

demonstrated that this significant difference was in lumbar CSF levels of T-Tau ( $p=0.04$ and $p=0.02$, respectively), whereas Tarnaris et al. (2011) [70] demonstrated a significant difference in ventricular CSF levels of T-Tau. All three studies $[15,51,70]$ found that the levels of T-Tau were higher in shunt-non-responsive patients. On the other hand, six studies reported no differences between levels of T-Tau in patients who were shunt-responsive and those who were shunt-non-responsive. Abu Hamdeh et al. (2018) [1], Ågren-Wilsson et al. (2007) [4], Hong et al. (2018) [33], Tullberg et al. (2008) [73], and Vanninen et al. (2021) [74] found no differences in the levels

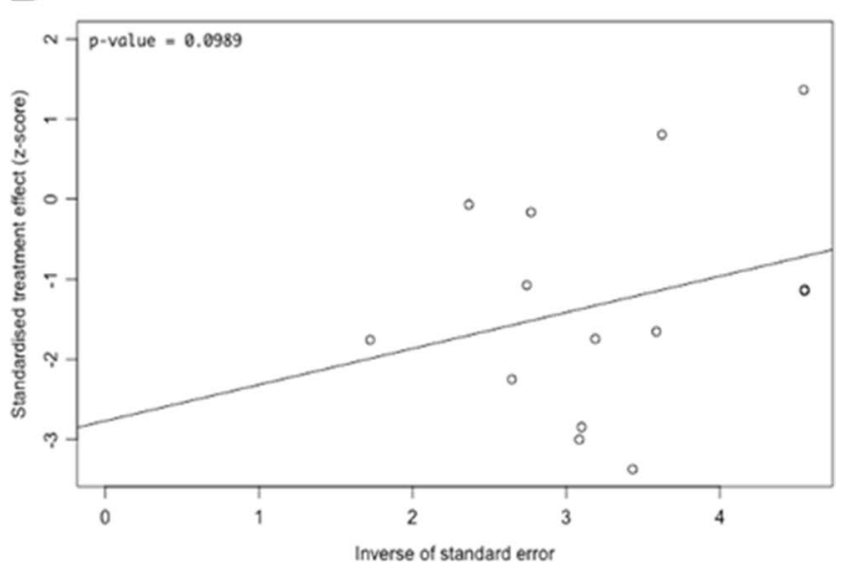

used and counted multiple times due to reporting on multiple biomarkers indicating presence and degree of publication bias is shown). $p$-value $<0.05$ is deemed significant and implicates publication bias. Egger's asymmetry test yielded $p=0.0989$, calculated running an Egger's regression (see Egger's regression line) on the collated logDOR and standard errors of all data used in the meta-analysis $(n=14)$

of T-Tau in lumbar CSF between shunt responders and shunt non-responders, and Craven et al. (2017) [15] found no differences in the levels of ventricular T-Tau between shunt-responsive and shunt-non-responsive patients. However, Migliorati et al. (2020) [51] performed a univariate logistic regression showing that lumbar CSF levels of T-Tau were significantly associated with the worse clinical outcomes following shunt surgery if lumbar CSF T-Tau levels exceeding $731.7 \mathrm{ng} / \mathrm{l}(p=0.024)$. The best cut-off identified by ROC analysis was at the level of $233.9 \mathrm{ng} / \mathrm{L}$, with a sensitivity of $81.8 \%$ and a specificity of $72.4 \%$ for predicting shunt response. 


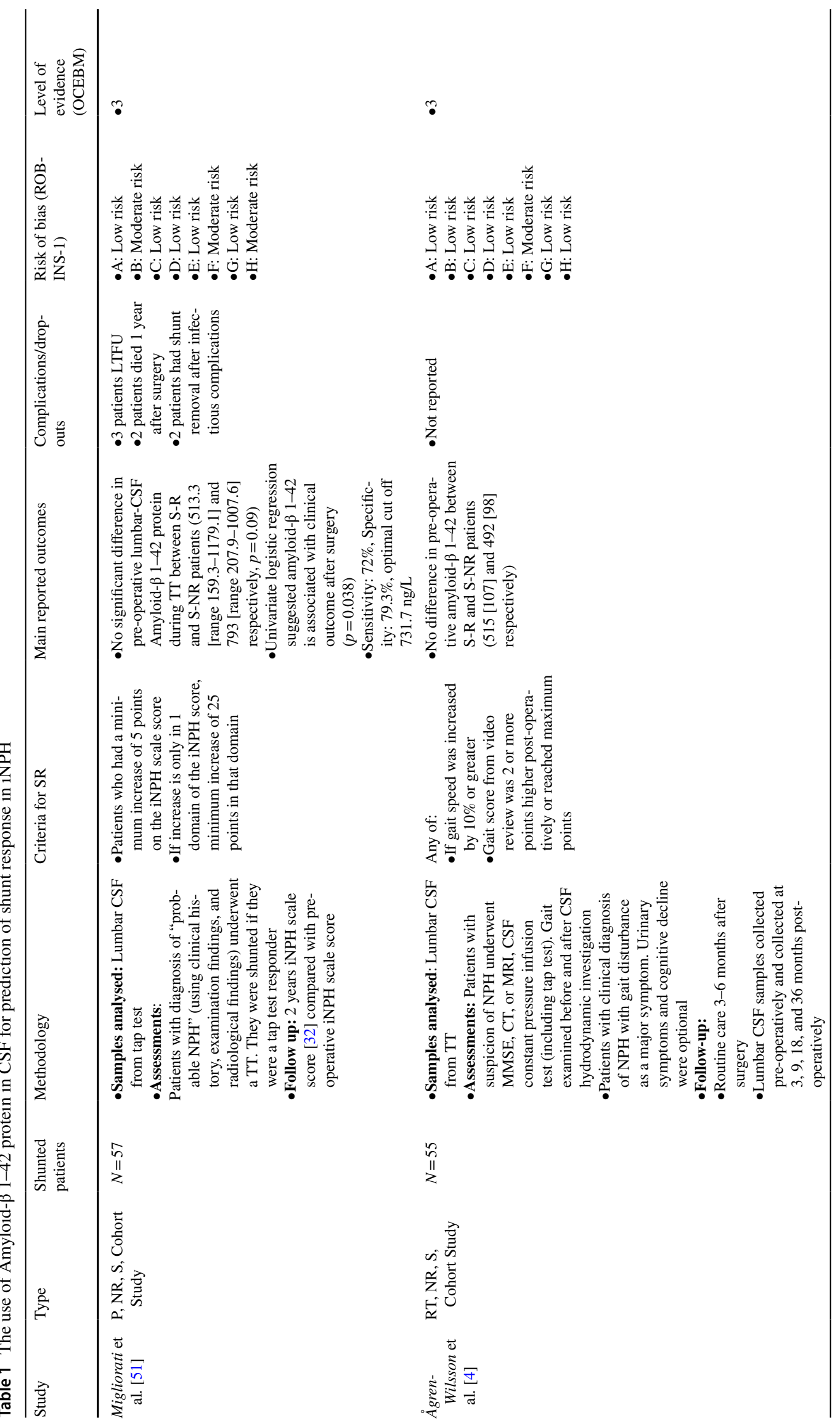




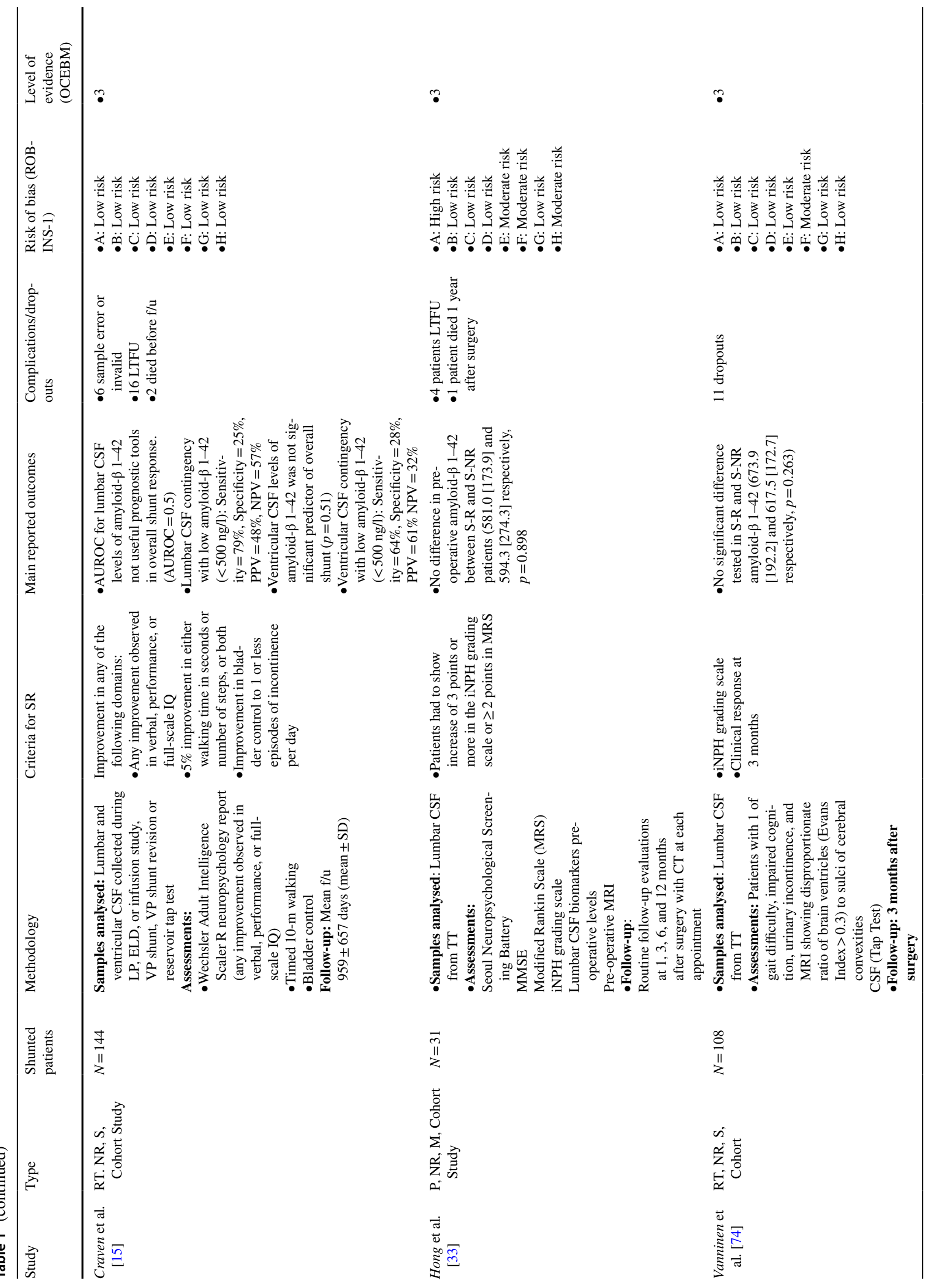




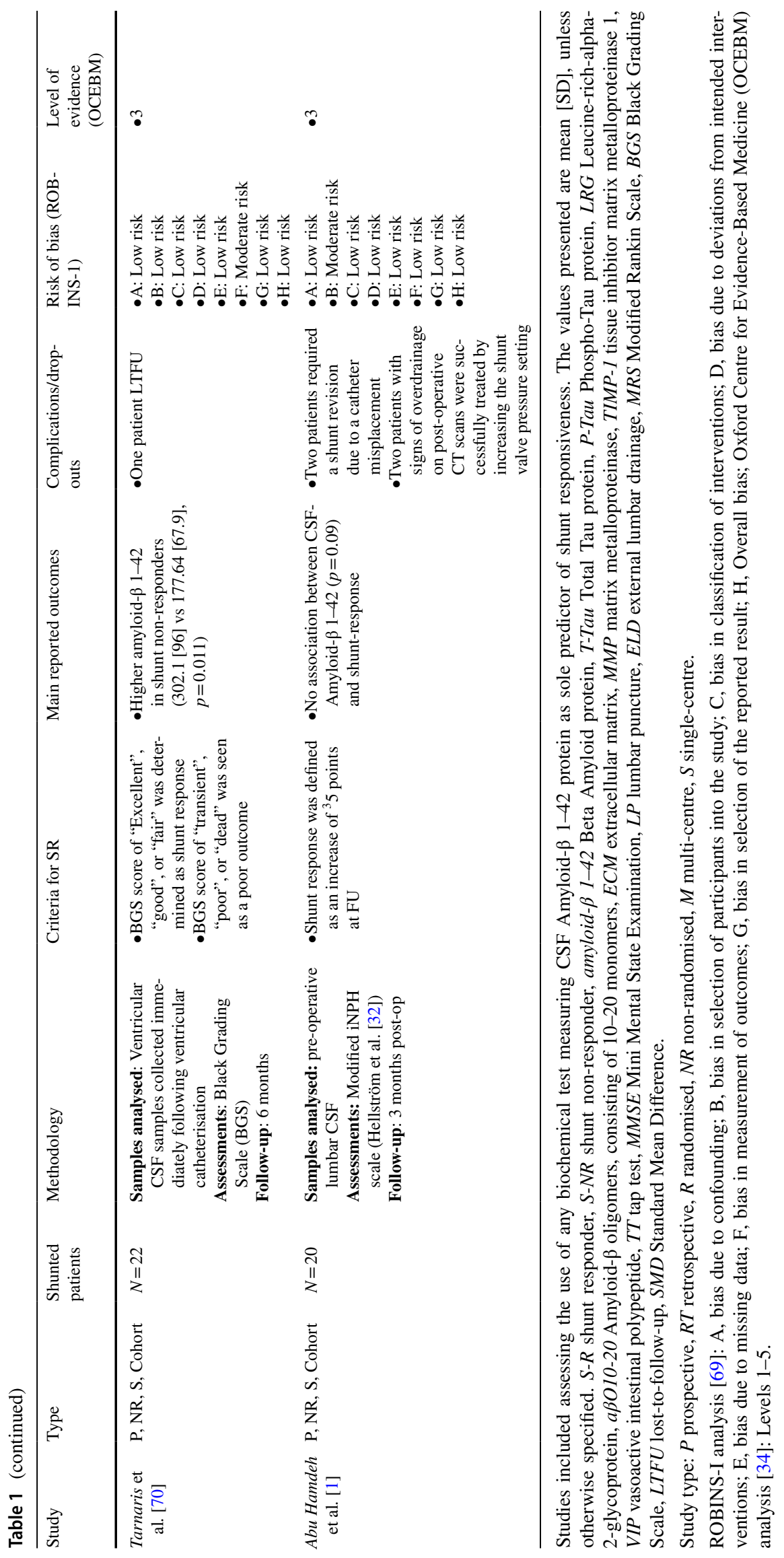




\section{Phosphorylated-Tau}

Five studies analysed the use of P-Tau to predict shunt responders (Table 2) [1, 4, 33, 51, 74]. Migliorati et al. (2020) [51] reported a significantly higher lumbar CSF level of P-Tau in shunt non-responsive patients $(p=0.01)$. This finding was not reciprocated by four other studies, which showed no significant prognostic value in lumbar P-Tau [1, 4, 33, 74]. Migliorati et al. (2020) [51] also performed a univariate logistic regression for P-Tau, demonstrating that lumbar CSF levels of P-Tau exceeding $32.2 \mathrm{ng} / \mathrm{L}$ were significantly associated with poor shunt response $(p=0.009)$. The best cut-off identified was at the level of $32.2 \mathrm{ng} / \mathrm{L}$, with a sensitivity of $81.8 \%$ and a specificity of $72.4 \%$.

\section{Phosphorylated-Tau/amyloid- $\beta$ 1-42 ratio}

Two studies examined the difference in pre-operative P-Tau/ amyloid- $\beta$ 1-42 ratio between shunt-responsive and shuntnon-responsive patients (Table 2). Both studies by Hong et al. (2018) [33] and Patel et al. (2012) [58] found that there was a significantly lower ratio in patients who were shuntresponsive versus those who were shunt-non-responsive ( $p=0.041$ and $p=0.032$, respectively).

\section{Total-Tau/amyloid- $\beta$ 1-42 ratio}

Two studies explored the difference in pre-operative T-Tau/ amyloid- $\beta$ 1-42 ratio between shunt-responsive and shuntnon-responsive patients (Table 2). Both studies by Craven et al. (2017) [15] and Hong et al. (2018) [33] found that there was no significant difference in the ratio between patients who were shunt-responsive versus those who were shuntnon-responsive ( $p=0.64$, and $p=0.564$, respectively).

\section{Neurofilament light protein}

The axonal integrity biomarker NFL protein, found in lumbar CSF, was analysed, for how its levels in the CSF are related to shunt response by two studies $[4,73]$ (Table 3 ). Both reported no significant difference in post-shunt outcomes in pre-operative NFL between shunt-responsive and shunt-non-responsive patients ( $\mathrm{ggren}-W i l s s o n$ et al. (2007) [4], $p=0.18$; Tullberg et al. (2008) [73], $p>0.05$ ).

\section{Albumin}

One study, by Tullberg et al. (2008) [73], explored the relationship between levels of albumin and shunt outcomes (Table 3). The authors found that there was no significant difference in pre-operative levels of total albumin or the $\mathrm{CSF} /$ serum albumin ratio ( $p$ values not reported) between shunt-responsive and shunt-non-responsive patients.

\section{Vasoactive intestinal peptide}

Differences in VIP, a neuropeptide released by immune cells and neurons found widely in the central nervous system [17], were examined by two studies with mixed results for its use to predict shunt response (Table 3). Tullberg et al. (2008) [73] reported no significant difference in pre-operative lumbar CSF VIP concentration between shunt-responsive and shunt-non-responsive patients ( $p$-value not reported). In contrast, Johansson et al. [39] reported that pre-operative levels of VIP $<20 \mathrm{pmol} / \mathrm{L}$ were predictive of positive shunt response; however, the authors failed to delineate this claim with the data presented in their paper.

\section{Sulfatide}

Sulfatide is a component of the myelin sheath in the central and peripheral nervous systems [18]. Two studies, Ågren-Wilsson et al. (2007) [4] and Tullberg et al. (2008) [73], explored the levels of sulfatide and shunt outcomes (Table 3). However, both studies reported that the differences in levels of sulfatide between patients who were shuntresponsive and those that were shunt-non-responsive were insignificant. Both studies did not report $p$-values, but the value for Ågren-Wilsson et al. (2007) [4] was calculated to be 0.84 .

\section{Leucine-rich alpha-2 glycoprotein}

Vanninen et al. (2021) [74] examined the correlation between leucine-rich alpha-2 glycoprotein (LRG) in iNPH patients undergoing shunt surgery (Table 3 ). LRG is a novel biomarker that is indicative of inflammation, especially autoimmune conditions [66]. The authors reported that although LRG levels are raised in iNPH, this protein is not predictive of shunt response $(p=0.636)$.

\section{ECM proteins}

Minta et al. (2021) [52] looked at the differences in levels of extracellular matrix proteins (Brevican, Neurocan, matrix metalloproteinases (MMP)) and tissue inhibitor matrix metalloproteinase 1 (TIMP-1) between shunt-responsive and shunt-non-responsive patients (Table 3). They found that there were no significant differences in the levels of Brevican, Neurocan, MMP, or TIMP-1.

\section{Proteomics}

Scollato et al. [65] explored proteomic differences of ventricular CSF in shunt-responsive and shunt-non-responsive patients through the means of 2D-Gel electrophoresis and matrix-assisted laser desorption/ionisation and time of flight 
mass spectrometry (MALDI TOF MS) (Table 3). Shunt-nonresponsive patients' samples were found to have increased expression of Clusterin, Apo J, Apo E, and GFAP, whereas a2-HS-GP and a1b-GP expression was reduced in shuntnon-responsive patients.

\section{Genotyping proteins}

One study by Pyykkö et al. [60] looked at the distribution of the Apolipoprotein E (ApoE) genotype among patients with iNPH, specifically looking at the differences in the proportion of the ApoE4 genotype by analysing a venous blood sample (Table 3 ). In the population studied, there was no difference in the distribution of ApoE genotypes $(p=0.47)$, nor in the proportion of ApoE4 carriers $(p=0.72)$.

\section{Statistical results}

\section{Meta-analysis}

The meta-analysis was conducted for the following CSF biomarkers, which met the inclusion criteria for meta-analysis (studies per biomarker: $n>2$ ): amyloid- $\beta$ 1-42, P-Tau, and T-Tau. For amyloid- $\beta 1-42$, four studies [4, 33, 51, 74], two scoring low and two scoring moderate risk, were included with a pooled sample size of $n=254$ shunted patients, and the pooled random effects size estimate, comparing shuntresponsive to shunt-non-responsive patients, was -0.10 SMD (CI 95\%: - 1.03-0.82), with $t=-0.35(p=0.75)$ (Fig. 4). For lumbar CSF P-Tau, four studies were included $[4,33,51,74]$, two scoring low and two moderate risk of bias, with a pooled sample size of $n=254$ shunted patients, and the pooled random effects size estimate was -0.55 SMD (CI 95\%: - 1.06-(-0.03)), with $t=-3.40(p=0.04)$ (Fig. 5). For T-Tau six studies [4, 33, 51, 70, 73, 74], three scoring low, two moderate, and one scoring critical risk of bias, with a pooled sample size of $n=310$ shunted patients, were included (one ventricular CSF [70], five lumbar CSF $[4,33,51,73,74]$, and the pooled random effects size estimate was -0.50 SMD (CI 95\%: - 0.88-(-0.12)), with $t=-3.34(p=0.02)$ (Fig. 6). Overall, the meta-analyses indicated significantly higher levels of CSF P-Tau and T-Tau in shunt-non-responsive than shunt-responsive iNPH subjects $(p<0.05)$, but not for amyloid- $\beta 1-42$.

\section{Sensitivity analysis and meta-regression}

A sensitivity analysis was performed by firstly omitting studies with "critical" overall risk of bias on the ROBINSI tool [69] (Table 1, Table 2, Table 3). The only study that fulfilled this criterion was Tullberg et al. [73], which is one of the studies included in the T-Tau subgroup analysis.
Hence, it was omitted in an additional meta-analysis for T-Tau (Supplementary Fig. 1). The meta-analysis yielded a SMD of -0.56 (95\% CI: $-0.98-(-0.14)), p=0.02$. Hence, this study did not affect the overall statistical validity of the initial meta-analysis for T-Tau, as the SMD remained similar to the original SMD (Fig. 6) and the $p$-value remained significant. Subsequently, a single-variate meta-regression was performed for each biomarker (T-Tau, P-Tau, and amyloid- $\beta$ 1-42). The meta-regressions scored the influence of all covariates on the overall effect size of each biomarker (standard mean difference) to be insignificant for P-Tau and amyloid- $\beta$ 1-42 (Table 4). However, for T-Tau, the explicit inclusion of patients with neurological comorbidities was found to be significant, with a regression coefficient of -0.6768 (95\% CI: $-1.1243-(-0.2294)$ ), $p=0.0137$ (Table 4, for graphical visualisation, see Supplementary Fig. 2). This implies that the inclusion of neurologically comorbid patients negatively skewed the SMD of CSF T-Tau levels between shunt responders and shunt non-responders. To further assess the impact of the covariate "neuro," multiple multi-variate meta-regression models for T-Tau were built using the covariate "neuro" in combinations with the other covariates (Table 5). For most combinations, doing this rendered the regression coefficient of "neuro" to be non-significant $(p>0.05)$. However, in combination with the covariates "sample" and "date", the regression coefficient of "neuro" yielded 1.0409 (CI 95\%: 0.3674-1.7143), which was significant at $p=0.0219$. This implies that in this combination, "neuro" positively skewed the SMD of the T-Tau meta-analysis. Finally, to assess the statistical effect of "neuro" on the effect size of T-Tau for shunt response prediction, another subgroup meta-analysis for T-Tau was performed, and now the studies that included neurologically comorbid patients were omitted, namely Ågren-Wilsson et al. [3] and Migliorati et al. [51]. However, this did not have a strong effect, as the SMD remained similar at -0.36 (CI 96\%: $-0.68-(-0.04))$ and remained significant at $p=0.04$ (Supplementary Fig. 3).

\section{Albatross plot}

An albatross plot indicating and visualising the effect size as standard mean difference (SMD) was synthesised for studies that met the inclusion criteria for albatross plotting (studies per biomarker $n=2$ ), but not for the meta-analysis (studies per biomarker $n=>2$ ). Four studies were included: two with low, one with moderate, and one with critical risk of bias. The biomarkers displayed in the albatross plot were NFL $[4,73]$, Sulfatide $[4,73]$, and T-Tau/ amyloid- $\beta$ 1-42 ratio levels $[15,33]$ in lumbar CSF samples of shunt-responsive patients compared to shunt-non-responsive patients (Fig. 7). As can be seen on the graph, all markers are increased in 


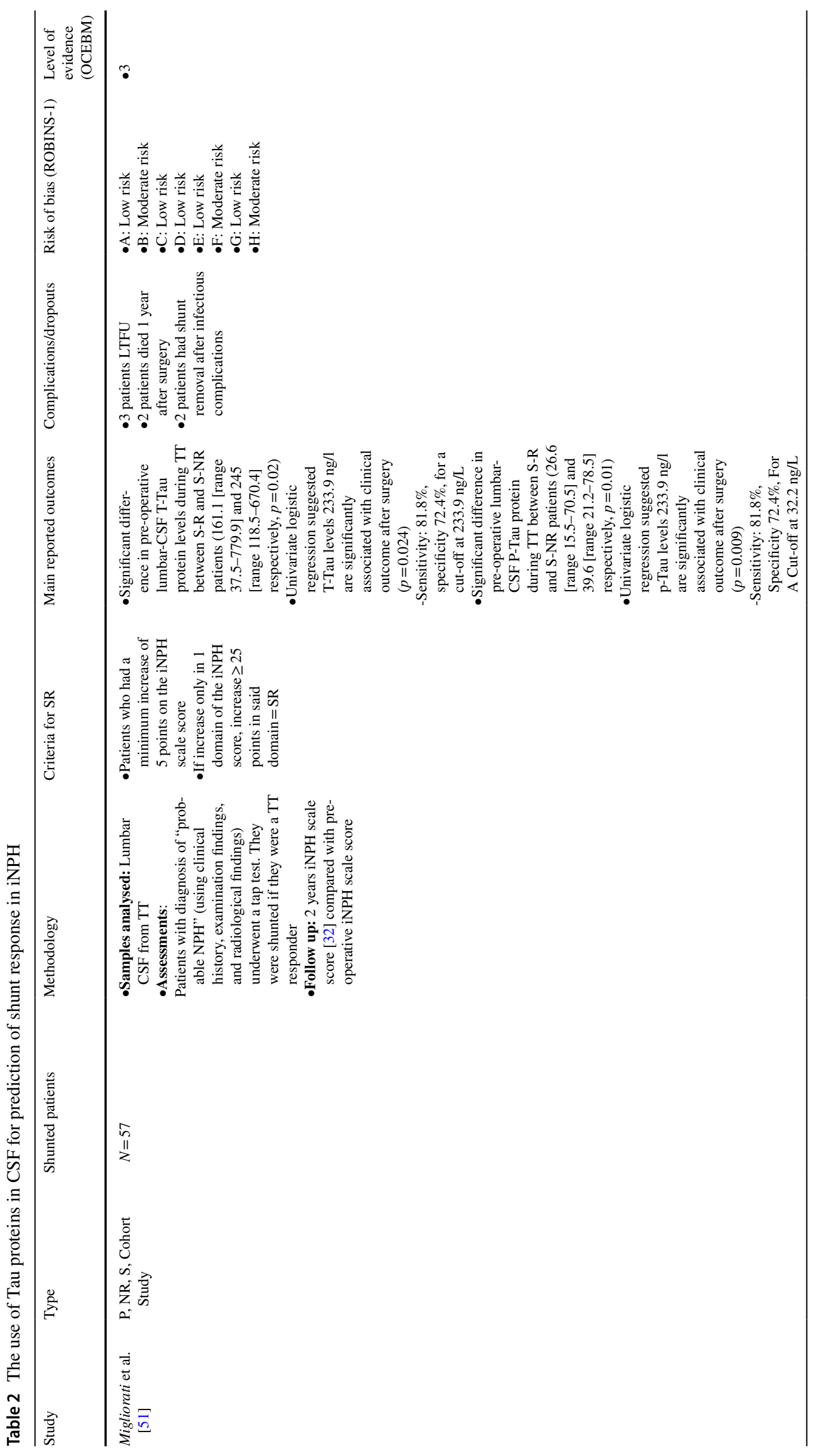




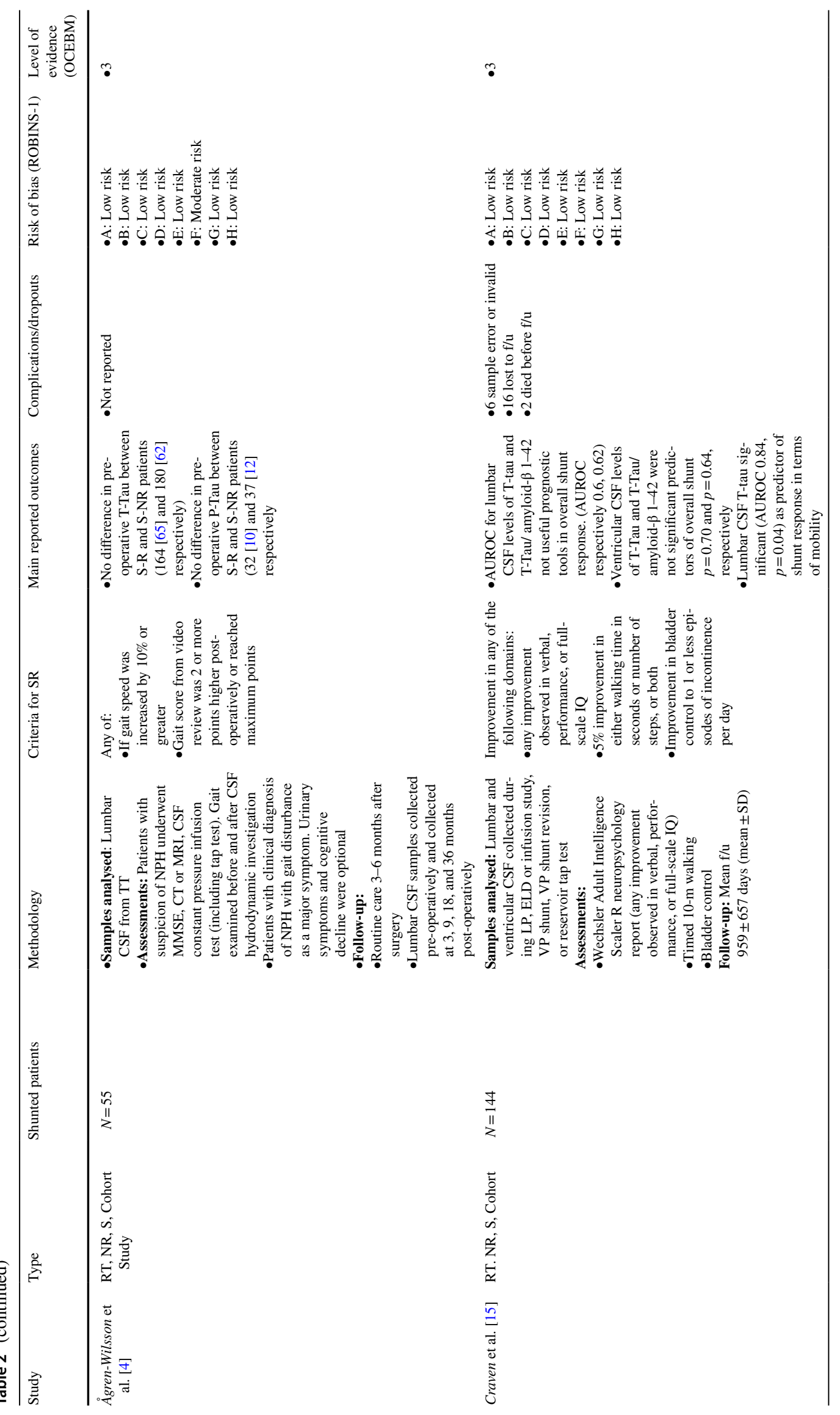




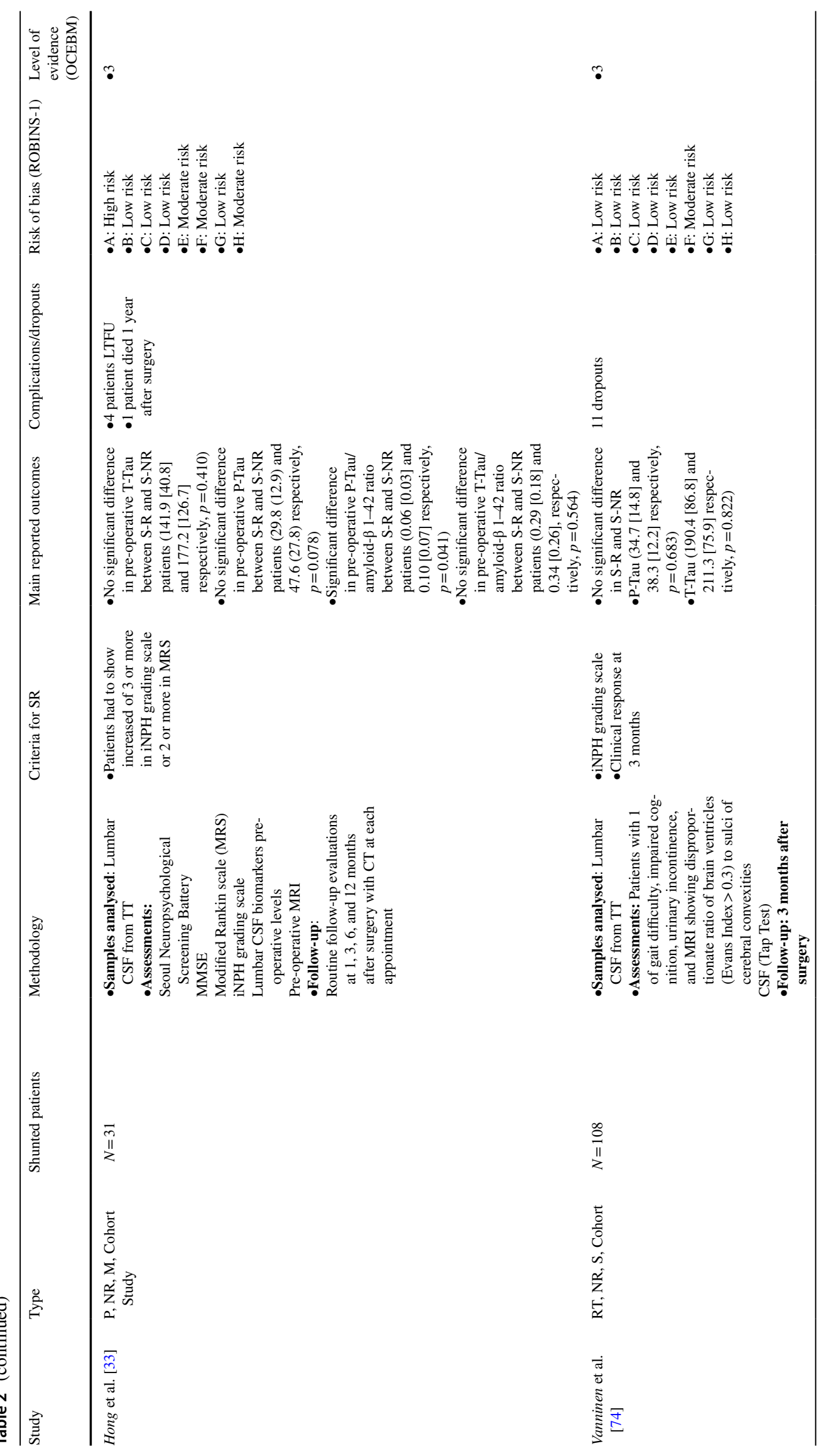




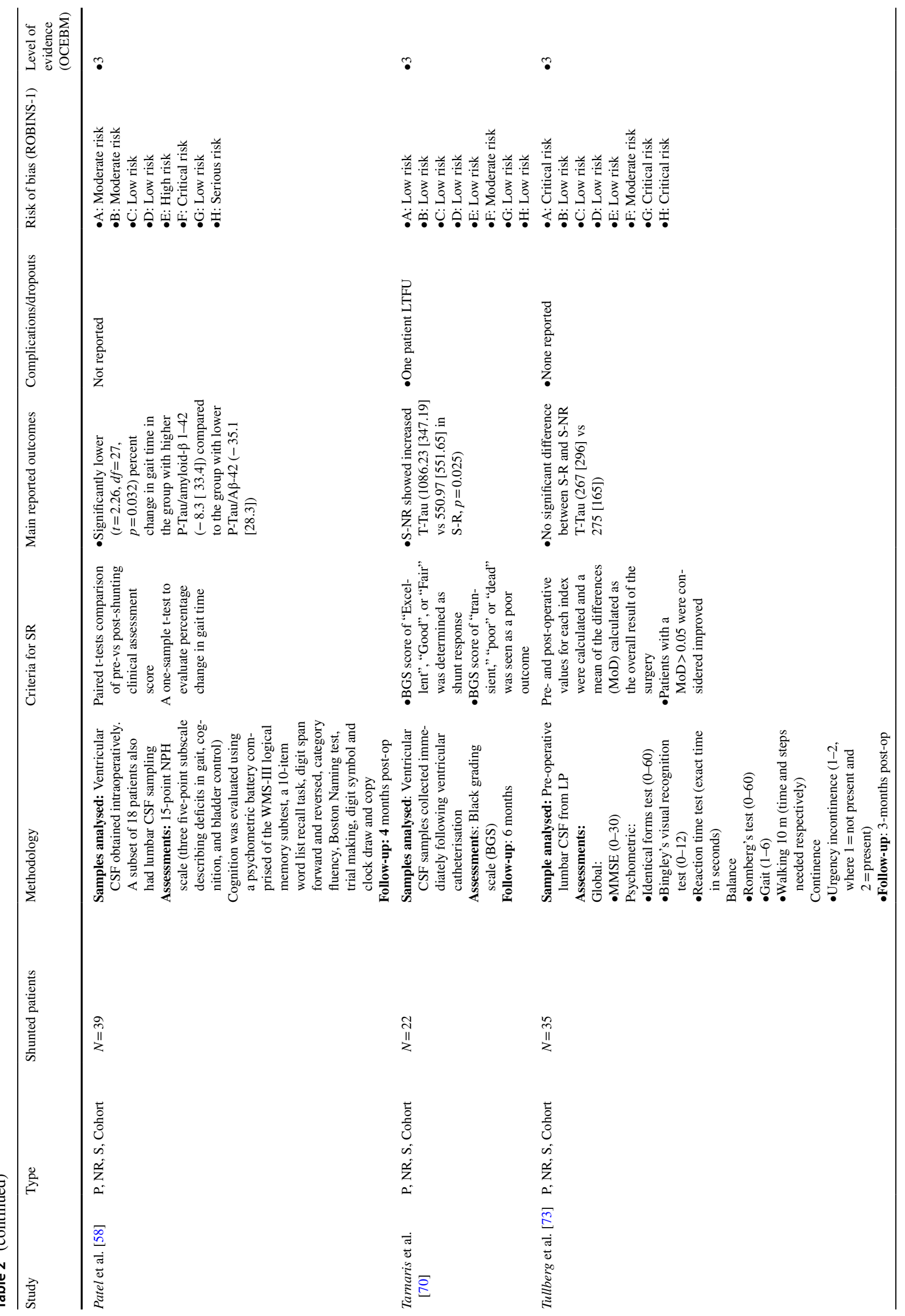




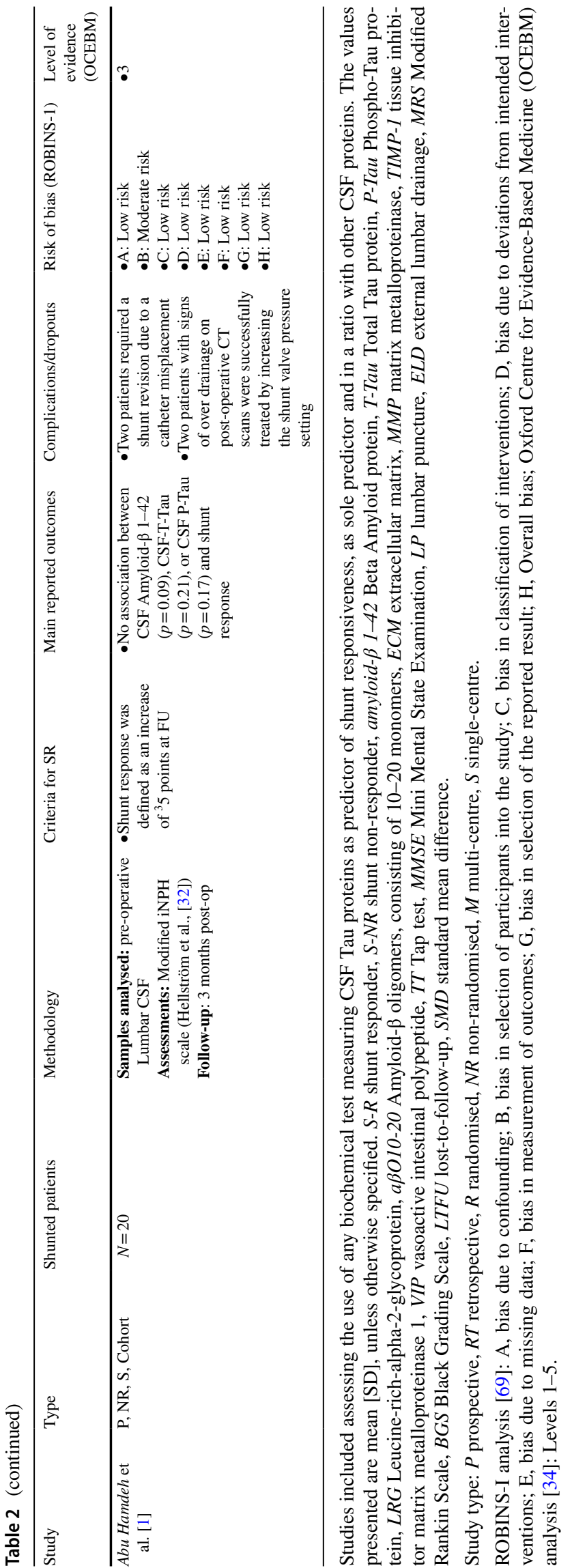

shunt-responsive patients compared to shunt-non-responsive; however, all studies are insignificant $(p>0.05)$. Sulfatide is, in numeric terms, the most insignificant biomarker for differentiating between shunt-responsive and shunt-nonresponsive patients and has an SMD between 0 and 0.15, followed by T-Tau/ amyloid- $\beta$ 1-42 ratio with SMD between 0.15 and 0.25 , and lastly, and performing best, is NFL with SMD between 0.25 and 0.5 .

\section{Measurement of shunt response}

The literature refers to several ways of characterising iNPH patients as shunt responders or shunt non-responders (Tables 1-3). The most common method was the usage of a scoring system before and after the shunt procedure used by nine studies $[1,15,33,51,52,58,65,70,73]$. If the scores had improved by a certain number, then the patient was categorised as shunt-responsive. The most common scale/scoring system used was the iNPH scale, used by Abu Hamdeh et al. (2018) [1], Hong et al. (2018) [33], Migliorati et al. (2021) [51], Minta et al. (2021) [52], Patel et al. (2012) [58], and Vanninen et al. (2021) [74]. Tarnaris et al. (2011) [70] used the Black Grading Scale (BGS) which stratified patients by how much their iNPH grading score improved. Those with scores of "Excellent", "Good", and "Fair" were considered shunt responders. Tullberg et al. (2008) [73] utilised a protocol they devised in previous studies that was also a grading scale that incorporated the mini-mental state examination (MMSE), psychometrics, balance, and continence. Craven et al. (2017) [15] used the Wechsler Adult Intelligence Scale as a validated outcome measure [76]. Pyykkö et al. (2012) [60] considered an improvement in any of the core symptoms as positive shunt response- these were improvements in gait, continence, or memory. ÅgrenWilsson et al. (2007) [4] only looked at improvement in gait as means to classify a patient as shunt-responsive.

\section{Complications}

The included studies did not specify complications related to obtaining ventricular or lumbar CSF for biomarker analysis; the reported complications were only related to ventriculoperitoneal shunt insertion. Two patients required a shunt revision due to a misplaced proximal catheter outside the ventricle or distal catheter dislocation as visualised by post-operative computer tomography in the study performed by Abu Hamdeh et al. (2018) [1]. In the same study, two patients experienced catheter over-drainage, which was rectified by increasing the shunt valve pressure setting [1]. In the study by Migliorati et al. (2021) [51], two patients experienced infection at the catheter site and therefore had the shunt removed. In that study, of the total study population, 24 patients were lost to follow-up [51]. Three patients died 


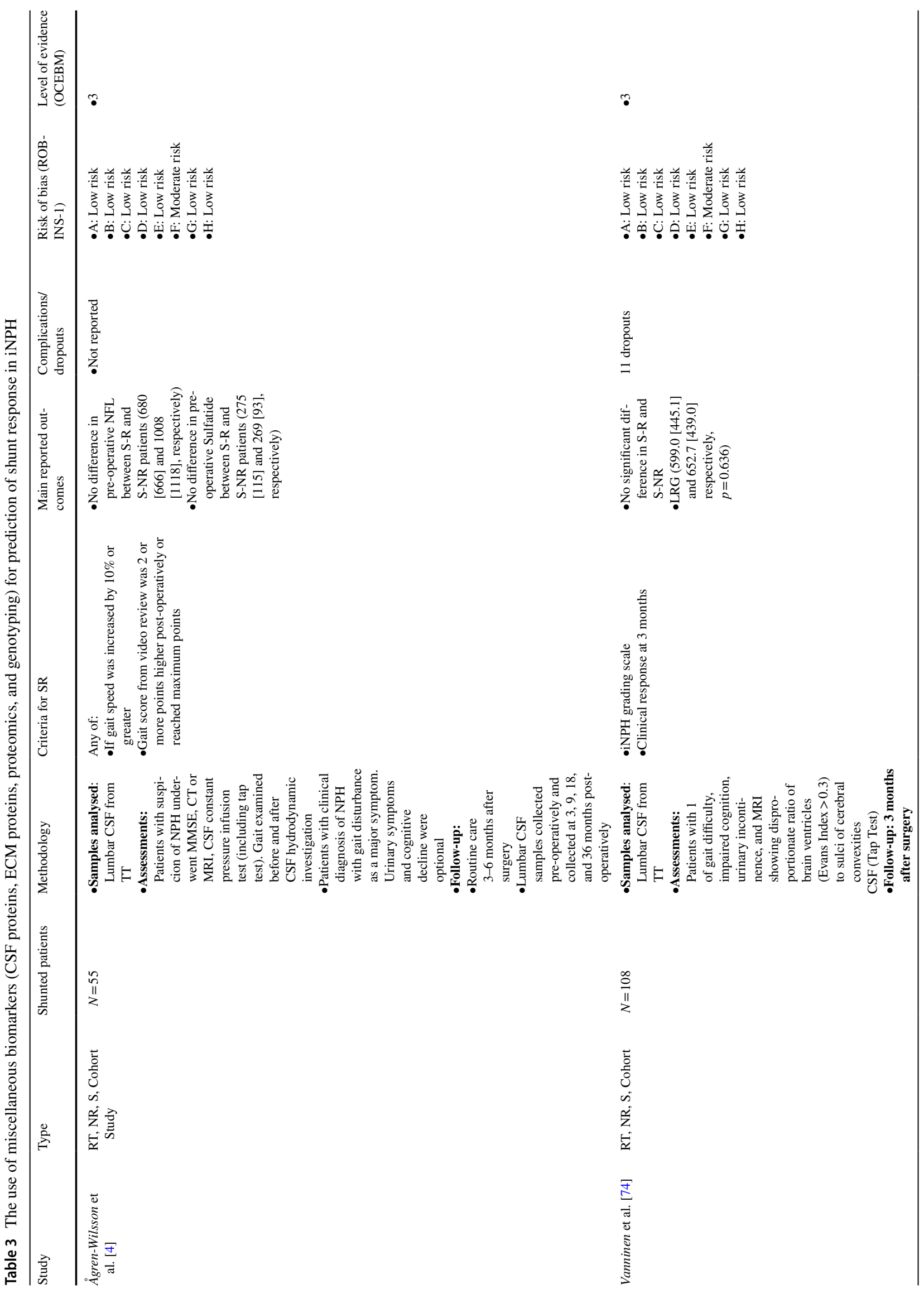




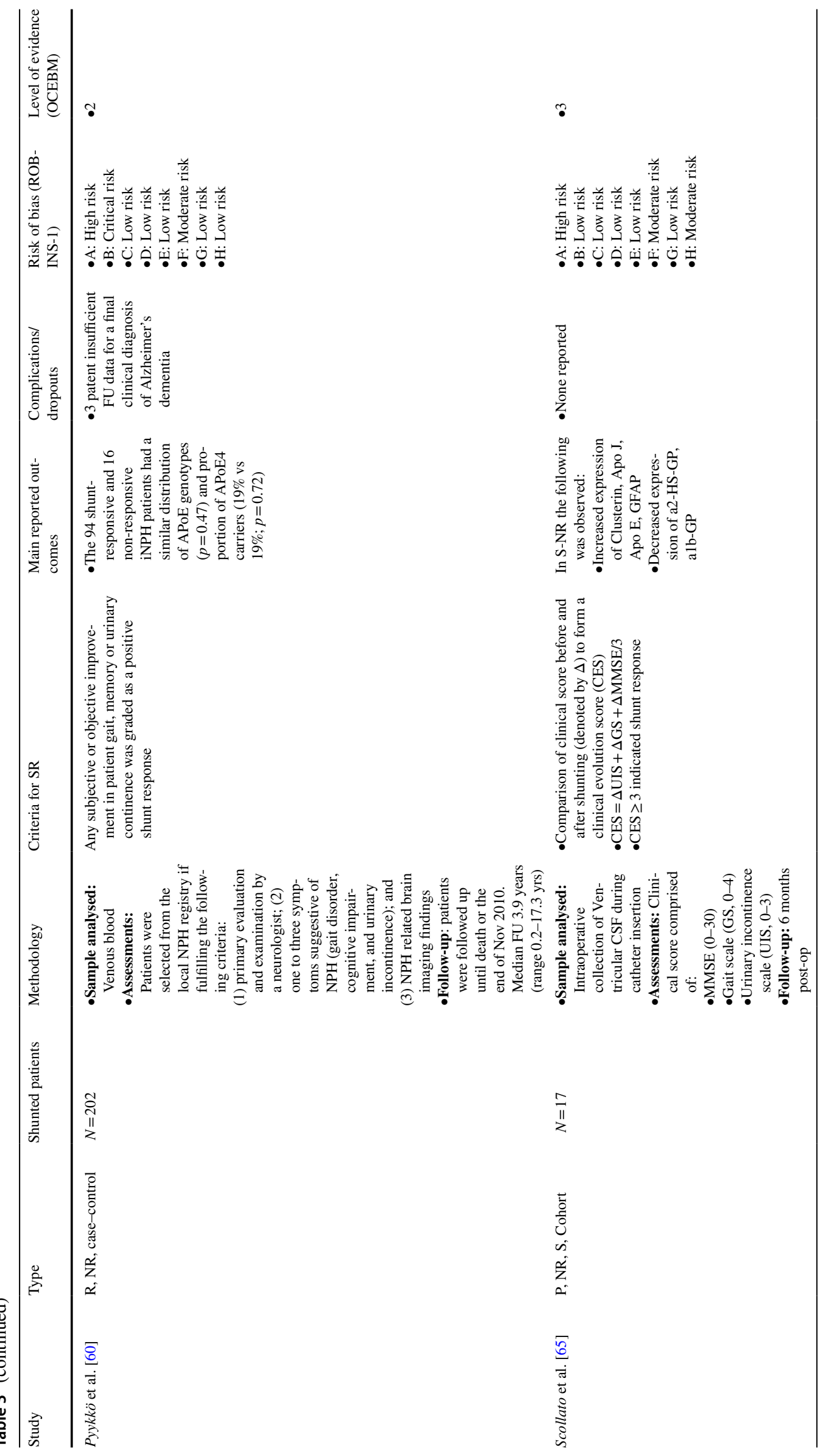




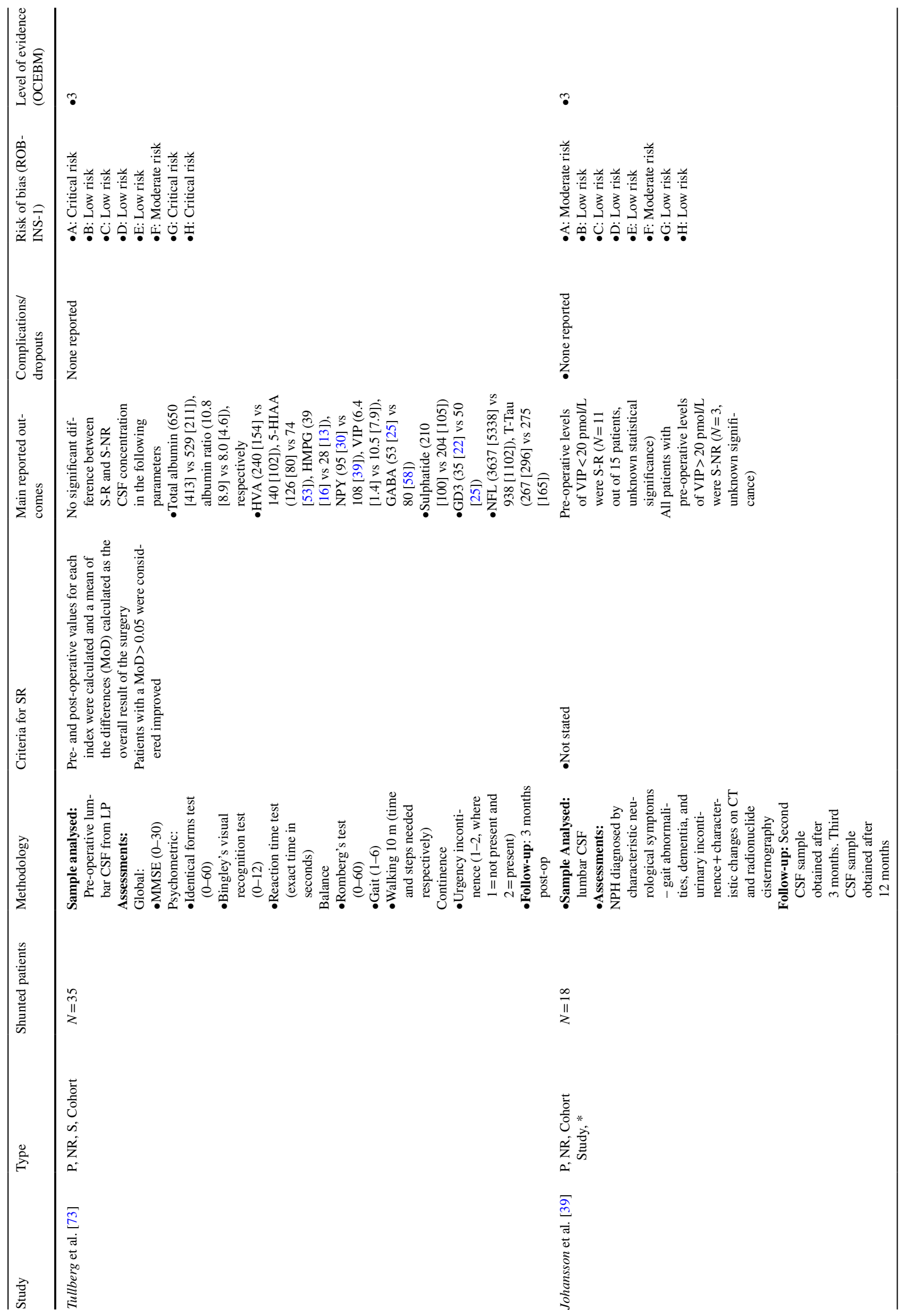




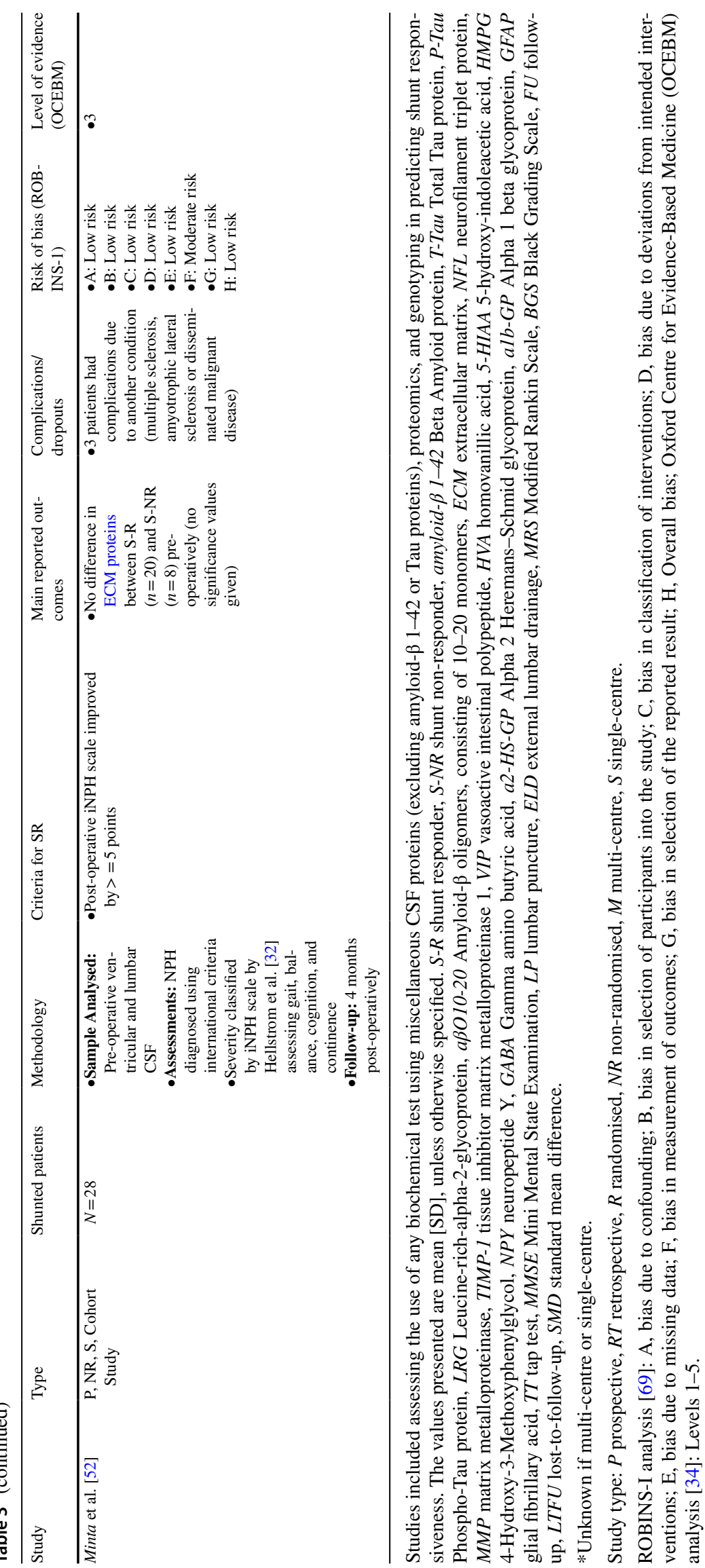


within 1 year of shunt surgery [33, 51]. Two patients died before follow-up [15].

\section{Discussion}

The main finding of this systematic review and meta-analysis is that there were significantly increased CSF levels of T-Tau and P-Tau in iNPH patients who do not respond to shunt surgery. On the other hand, CSF levels of amyloid- $\beta$ 1-42 did not differ significantly between shunt non-responders and shunt responders.

The presence of increased levels of the Tau proteins in the CSF is an indicator of neurodegeneration. Tau proteins are abundant in neurons and help maintain axon microtubule skeleton stability. Pathologically elevated levels of particularly P-Tau, a hyperphosphorylated form of Tau, have previously been associated with neurodegenerative disorders such as Alzheimer's and Parkinson's diseases [43]. Hence, multiple studies have tried to identify the value of P-Tau and T-Tau in iNPH shunt response prediction, albeit with mostly insignificant differences in levels between shunt responders and shunt non-responders [1, 4, 15, 33, 51, 58, 70, 73, 74]. The authors believe the latter to be due to a sample size error in these studies. Upon pooling all study data on P-Tau and T-Tau, respectively, our meta-analysis found that T-Tau and P-Tau levels were significantly increased in shunt-nonresponsive iNPH ( $p=0.02$ and $p=0.04$, respectively). This discrepancy between Tau protein levels may have several explanations. Elevated levels of Tau protein could be an early manifestation of $\mathrm{AD}$ [1], which may have a negative impact on the patient's performance in post-operative neurological assessment tests, weakening or completely masking the associated positive change in symptomology in iNPH pathology after CSF diversion. Human in vivo tracer studies showed impaired clearance of a CSF tracer in iNPH patients [23, 63], which may be one mechanism behind increased CSF levels of metabolites such as Tau. In line with this, Migliorati et al. (2021) [51] hypothesised that higher levels of P-Tau and T-Tau may arise from CSF stasis and subsequent aggregation of toxic Tau protein types in patients with long-standing iNPH or progressed disease. It is argued that in these scenarios, irreversible parenchymal damage is present, which hinders response to shunt surgery. However, none of the existing theories regarding elevated Tau levels in shunt non-responders has been proven, and thus more evidence is needed to consolidate them. In line with the findings of our meta-analysis, Migliorati et al. (2021) [51] went further and examined the diagnostic efficiency of P-Tau and found that the best cut-off for differentiating shunt responders from shunt non-responders was $32.2 \mathrm{ng} / \mathrm{l}$, with a sensitivity of $81.8 \%$ and a specificity of $72.4 \%$. Similarly, for T-Tau the best cut-off identified was $233.9 \mathrm{ng} / \mathrm{l}$ with a sensitivity and specificity respectively of $81.8 \%$ and $72.4 \%$. However, given that this is a single-study finding, as well as the fact that Migliorati et al. (2021) [51] excluded patients comorbid with iNPH mimics from their study which limits the generalisability of their findings, further studies using ROC analyses must be conducted to assess the diagnostic efficiency of Tau biomarkers more reliably. Nonetheless, the results from our meta-analyses regarding Tau levels were also consolidated in brain biopsy studies [1], in which shunt non-responders had higher levels of Tau protein than shunt responders. Given these findings and the fact that the relative complication risk of CSF removal is not increased by biomarker analysis, as iNPH patients invariably undergo some form of CSF removal, the inclusion of biochemical markers in the shunt response prediction pathway of iNPH is logical and inevitable. Overall, the authors advocate for more research on the sensitivity and specificity of specifically the combined use of T-Tau and P-Tau CSF levels, as well as their associated ratios with amyloid- $\beta 1-42$, including specific cut-off levels. However, given the current lack of evidence on diagnostic efficiency and cut-offs, the authors do not recommend using CSF Tau protein biomarkers as sole predictors but as complementary variables, using the cut-off proposed by Migliorati et al. (2021) [51], alongside robustly proven clinical predictors such as intracranial pressure monitoring (ICPM) [19-22, 24, 25] and extended lumbar drainage (ELD) [71].

CSF amyloid- $\beta$ 1-42 has previously been reported to be lower in $\mathrm{AD}$, as a significant proportion of $\beta$-amyloid aggregates are fused into plaque fibrils, with particularly amyloid- $\beta$ 1-42 having an aggregation tendency due to its highly hydrophobic nature [6]. Hence, it was hypothesised whether this biomarker may be lower in shunt non-responsive iNPH $[1,51]$. Our meta-analysis found no significant difference in lumbar CSF amyloid- $\beta$ 1-42 between shunt responders and shunt non-responders $(p=0.75)$. However, the analysis only included three studies; hence, the findings are limited by the low sample size. Migliorati et al. (2021) [51] reported a sensitivity of $72.7 \%$ and $79.3 \%$ with an optimal cut-off at $731.7 \mathrm{ng} / \mathrm{l}$ for CSF amyloid- $\beta$ 1-42 when used to predict shunt response, but further studies are needed to consolidate their findings. Overall, the authors do not recommend CSF amyloid- $\beta$ 1-42 to be used as a variable in shunt response prediction, until more research proves a significant difference between shunt responders and shunt non-responders.

The existing literature on all other CSF biomarkers (ECM, VIP, LRG, NFL, Sulfatide, Albumin, Sulfatide) is extremely sparse, with none of these having been examined by more than two of the included studies; hence, it is not possible to make a robust conclusion on their use in the prediction of shunt-responsive iNPH. However, the rationale of using these biomarkers is often similar to the use of the 


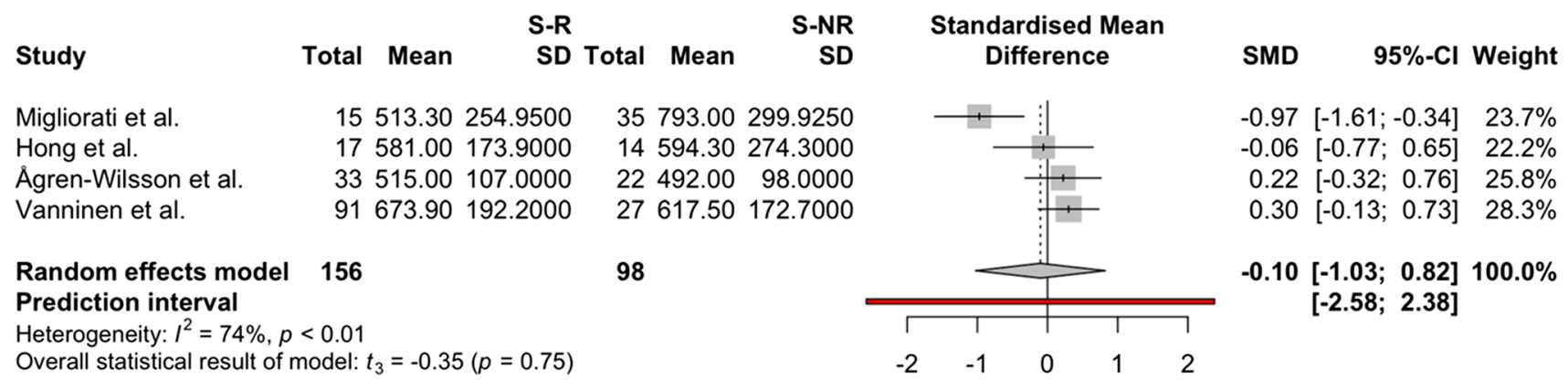

Fig. 4 A forest plot indicating and visualising the effect size in standard mean difference (SMD) of amyloid- $\beta$ 1-42 levels in lumbar CSF samples of shunt responder (S-R) versus shunt non-responder (S-NR) iNPH patients is shown ( $n=4$ studies) $[4,33,51,74]$. The size of the grey square of the SMD visual correlates to study sample size, and the straight line indicated the confidence interval. The diamond at the bottom indicates the overall pooled effect. The red bar below it indicates the prediction interval. Heterogeneity is indicated by the chi-squared statistic $\left(I^{2}\right)$ with associated $p$-value. The $95 \%$ confidence intervals (CI) are shown in squared bracket ([]). Furthermore, for every study, the following are displayed: author, total number of $\mathrm{S}-\mathrm{R}$ and their respective mean level and standard deviation (SD) of amyloid- $\beta$ 1-42 lumbar CSF levels, as well as the respective values for S-NR, weighting of each study in percentage (\%). There was no significant difference in amyloid- $\beta$ 1-42 between S-R and S-NR groups

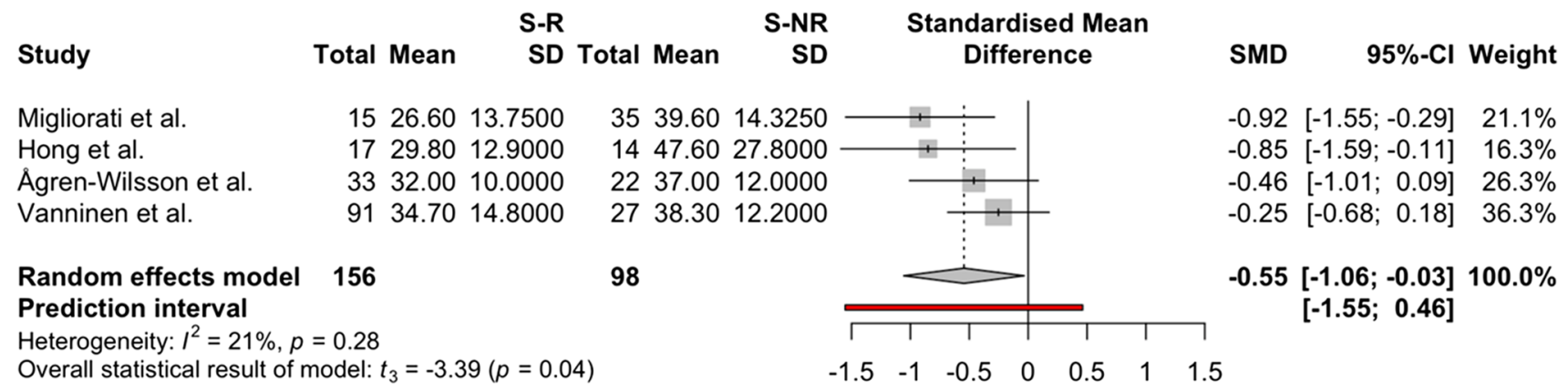

Fig. 5 A forest plot indicating and visualising the effect size in standard mean difference (SMD) of Phosphorylated-Tau (P-Tau) levels in lumbar CSF samples of shunt responder (S-R) versus shunt nonresponder (S-NR) iNPH patients is shown ( $n=4$ studies) $[4,33,51$, 74]. The size of the grey square of the SMD visual correlates to study sample size, and the straight line indicated the confidence interval. The diamond at the bottom indicates the overall pooled effect. The red bar below it indicates the prediction interval. Heterogeneity is

Tau proteins and amyloid- $\beta$ 1-42, with levels of nearly all the miscellaneous biomarkers, particularly sulfatide [11], being reported to be significantly altered in AD patients; hence, future research is highly warranted to examine their use further. The use of proteomics techniques, such as twodimensional electrophoresis coupled with MALDI TOF MS technique for the analysis of protein biomarkers, did not yield any statistically significant differences between shunt responders and shunt non-responders, and neither did the genotyping of blood samples. However, as the mentioned proteomics technique is the current gold standard in terms of accuracy to analyse proteins, the authors recommend future research to use this technique when analysing CSF biomarkers for shunt-responsive iNPH. Similarly, the use of genetic analysis in this context must be elucidated further [38], as indicated by the chi-squared statistic $\left(I^{2}\right)$ with associated $p$-value. The 95\% confidence intervals (CI) are shown in squared bracket ([]). Furthermore, for every study, the following are displayed: author, total number of S-R and their respective mean level and standard deviation (SD) of P-Tau lumbar CSF levels, as well as the respective values for S-NR, weighting of each study in percentage (\%). There was a significantly higher level of P-Tau in the S-NR group compared to the S-R group

most iNPH mimics have a proven genetic etiological basis, particularly Alzheimer's [9] and Parkinson's [40] diseases. However, the ethical implications of genetic testing are complex and must be managed carefully.

An important weakness of the existing literature on biomarkers for iNPH shunt response prediction is the lack of investigator blinding. In fact, only two studies $[1,15]$ reported blinding, with the remaining 11 studies reporting no blinding at all. One of these studies [58] only used a single investigator for data collection, which incurs a critical source of bias. Furthermore, two of the included studies had quite a significant dropout $[33,58]$, with Patel et al. (2012) [58] having an approximately 25\% dropout of the initial cohort, rates which quite possibly incur a significant source of selection bias. In these studies, patients who did 
Study

Tarnaris et al. Ågren-Wilsson et al. Migliorati et al. Hong et al.

Vanninen et al.

Tullberg et al.

Random effects model 201 Prediction interval

Heterogeneity: $I^{2}=19 \%, p=0.29$

Overall statistical result of model: $t_{5}=-3.34(p=0.02)$

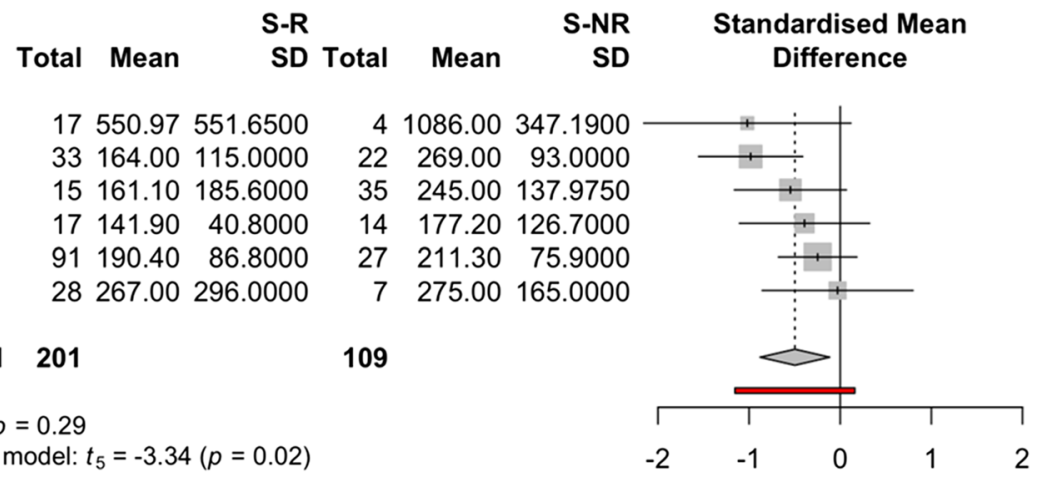

SMD

95\%-Cl Weight

$-1.02[-2.16 ; 0.12] \quad 6.5 \%$

$-0.98[-1.55 ;-0.41] \quad 20.3 \%$

$-0.55[-1.16 ; 0.07] \quad 18.2 \%$

$-0.39[-1.11 ; 0.32] 14.4 \%$

$-0.25[-0.68 ; 0.18] 29.3 \%$

$-0.03[-0.86 ; 0.80] 11.3 \%$

$-0.50[-0.88 ;-0.11] 100.0 \%$ $[-1.15 ; 0.16]$
Fig. 6 A forest plot indicating and visualising the effect size in standard mean difference (SMD) of Total-Tau (T-Tau) levels in lumbar $(n=5) \quad[4,33,51,73,74]$ and ventricular $(n=1$, Tarnaris et al. (2011) [70] samples of shunt responder (S-R) versus shunt non-responder (S-NR) iNPH patients is shown ( $n=6$ studies) [4, 33, 51, 70, 73, 74]. The size of the grey square of the SMD visual correlates to study sample size, and the straight line indicated the confidence interval. The diamond at the bottom indicates the overall pooled effect. The red bar below it indicates the prediction interval. Heterogeneity is

not respond to CSF removal via lumbar infusion test or CSF tap test likely dropped out and consequently leading to a skewed sample size in the shunt non-responder group. The negative effect of this on this meta-analysis is quite apparent in the analysis T-Tau (Fig. 6), with 109 patients in the shunt non-responder group, compared to 201 patients in the shunt responder group. The unequal sample size may indicated by the chi-squared statistic $\left(I^{2}\right)$ with associated $p$-value. The 95\% confidence intervals (CI) are shown in squared bracket ([]). Furthermore, for every study, the following are displayed: author, total number of S-R, and their respective mean level and standard deviation (SD) of T-Tau lumbar CSF levels, as well as the respective values for S-NR, weighting of each study in percentage. There was a significantly higher level of T-Tau in the S-NR group compared to the S-R group

have affected the statistical power of the analysis. Moreover, three studies $[1,51,60]$ excluded patients with neurodegenerative comorbidities categorically from the studies, which represent a grave methodological flaw that undermines the generalisability and clinical usefulness of their study results, as iNPH is a neurodegenerative disease itself with close overlap with Alzheimer's [46] and Parkinson's [54]
Table 4 Mixed-effects singlevariate meta-regression

\begin{tabular}{llll}
\hline & Total-Tau & Phosphorylated-Tau & Amyloid- $\beta$ 1-42 \\
\hline$\sim$ Covariates & Regression coefficients & & \\
$\sim$ age & 0.0119 & -0.0503 & -0.0410 \\
& $(-0.1361-0.1599)$ & $(-0.4015-0.3010)$ & $(-0.6861-0.6041)$ \\
$\sim$ females & 2.0664 & 9.0232 & 23.9811 \\
& $(-2.4792-6.6121)$ & $(-42.5615-60.6079)$ & $(-26.9236-74.8857)$ \\
$\sim$ sample & 0.0119 & 0.0067 & -0.0070 \\
& $(-0.0098-0.0144)$ & $(-0.0055-0.0188)$ & $(-0.0335-0.0475)$ \\
$\sim$ date & 0.0289 & -0.0070 & -0.0358 \\
& $(-0.0333-0.0910)$ & $(-0.1484-0.1343)$ & $(-0.2749-0.2033)$ \\
$\sim$ srm & 0.0119 & -0.1477 & -0.4444 \\
& $(-0.4259-1.1673)$ & $(-2.0210-1.7255)$ & $(-3.6846-2.7957)$ \\
$\sim$ neuro & $-\mathbf{0 . 6 7 6 8}[p=0.018]$ & 0.1477 & 0.4444 \\
& $(-0.0098-0.0144)$ & $(-1.7255-2.0210)$ & $(-2.7957-3.6846)$ \\
$\sim$ dropout & 0.1298 & -0.3633 & 0.0663 \\
& $(-1.1618-1.4214)$ & $(-2.3627-1.6361)$ & $(-3.5731-3.7057)$ \\
\hline
\end{tabular}

The results of the meta-regression of the meta-analyses of Total-Tau, Phosphorylated-Tau, and Amyloid- $\beta$ $1-42$, for each of the covariates (age, females, sample, srm, neuro, dropout) as independent variable to the dependent variable standard mean difference. In round brackets is the $95 \%$ confidence intervals. If significance is yielded (denoted with $*$ and bold regression coefficient), the $p$-value of the regression coefficient is shown in squared bracket only if significant, otherwise assume non-significance. Significance is assumed for $p<0.05$. The covariates age of the patient population (age), the proportion of females in percentage of overall population sample (females), the sample size (sample), the date of publication (date), the method of shunt response measurement (srm), explicit inclusion of patients with neurological comorbidities (neuro), and the dropout rate (dropout) for each study. The different explanatory variables were calculated singularly as sole covariates in separate meta-regressions. 


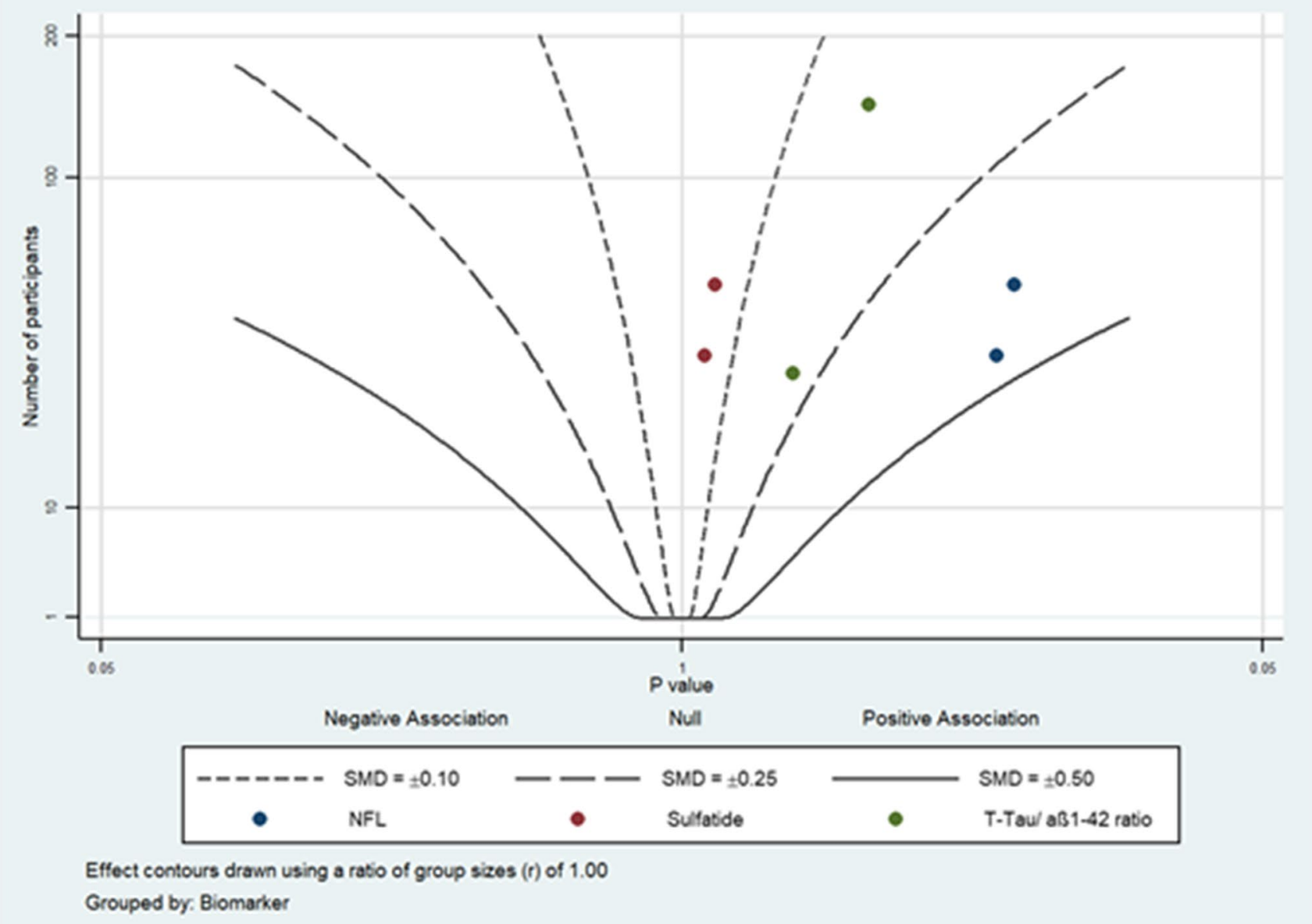

Fig. 7 An albatross plot indicating and visualising the effect size as standard mean difference (SMD) of neurofilament light (NFL), sulfatide, and Total-Tau (T-Tau)/amyloid- $\beta$ 1-42 (a 1 1-42) ratio levels in lumbar CSF samples of shunt responder (S-R) versus shunt nonresponder (S-NR) iNPH patients is shown, relative to $p$-value on the $\mathrm{x}$-axis and the sample size on the $\mathrm{y}$-axis ( $n=4$ studies). Three differently drawn lines indicate different SMD levels as outlined in the box. Each biomarker has its own-coloured dot as shown in the box.

diseases. Other studies [33, 65, 74] did not exclude iNPH patients with neurodegenerative conditions; however, they did not explicitly mention them at all when outlining patient characteristics even though neurological comorbidities are a significant confounder. This was reflected in the univariate meta-regression for T-Tau (Table 4), which showed that studies that included patients with neurological comorbidities skewed the SMD of T-Tau levels between shunt responders and shunt non-responders negatively. Even though it did not affect the overall findings of the T-Tau subgroup metaanalysis, the regression coefficient was significant (Table 4). Hence, in the future, studies should include patients with neurological comorbidities for more generalisable findings-however, the authors recommend that in the statistical analysis, patients with neurological comorbidities should be
Each dot represents a single study for the respective biomarker. Studies included for NFL: Ågren-Wilsson et al. (2007) [4], Tullberg et al. (2008) [73]. Studies included for Sulfatide: Ågren-Wilsson et al. (2007) [4], Tullberg et al. (2008) [73]. Studies included for T-Tau/ amyloid- $\beta$ 1-42: Craven et al. (2017) [15], Hong et al. (2018) [33]. All markers are increased in the S-R group compared to S-NR group, but the difference is not statistically significant

separately analysed and reported to allow for a fair comparison. Tullberg et al. (2008) [73] pooled shunt response results of iNPH patients and secondary iNPH in the final step of statistical analysis, constituting a critical error, as it makes it extremely questionable whether the study results apply to either pathology cohort, which are both completely different from each other in terms of disease aetiology. This may explain why their study, the only study scoring overall critical risk of bias (Table 3), was treated as an outlier in the meta-analysis and hence not included in the overall $t$ statistic (Fig. 6). Finally, none of the studies, except Craven et al. (2007) [15] and Migliorati et al. (2021) [51], provided calculations on diagnostic efficiency (area under curve value, diagnostic odds ratio, sensitivity, specificity) of the biomarkers at a certain cut-off level, which makes it impossible to 
Table 5 Mixed-effects multi-variate meta-regression

\begin{tabular}{|c|c|}
\hline & Total-Tau \\
\hline$\sim$ Covariates & $\begin{array}{l}\text { Regression coefficient } \\
\text { of neuro only }\end{array}$ \\
\hline$\sim$ neuro + age + females & $\begin{array}{l}0.4641 \\
\left(\begin{array}{lll}-0.4361 & 1.3644)\end{array}\right.\end{array}$ \\
\hline$\sim$ neuro + sample + date & $\begin{array}{l}\mathbf{1 . 0 4 0 9} *[p=0.0219] \\
(0.3674-1.7143)\end{array}$ \\
\hline$\sim$ neuro + females + date & $\begin{array}{l}0.0119 \\
(-0.0098-0.0144)\end{array}$ \\
\hline$\sim$ neuro + age + date & $\begin{array}{l}0.8769 \\
(-0.3688-2.1226)\end{array}$ \\
\hline$\sim$ neuro + females + sample & $\begin{array}{l}0.0604 \\
(-0.2397-1.2943)\end{array}$ \\
\hline
\end{tabular}

The results of the meta-regression of the meta-analyses of TotalTau, Phosphorylated-Tau, and Amyloid-Beta 1-42, for the covariate "neuro" in combination with the other covariates (age, females, sample, srm, dropout) as independent variable to the dependent variable standard mean difference. In round brackets is the $95 \%$ confidence intervals. If significance is yielded (denoted with * and bold regression coefficient), the $p$-value of the regression coefficient is shown in squared bracket if significant only, otherwise assume non-significance. Significance is assumed for $p<0.05$. The covariates age of the patient population (age), the proportion of females in percentage of overall population sample (females), the sample size (sample), the date of publication (date), the method of shunt response measurement (srm), explicit inclusion of patients with neurological comorbidities (neuro), and the dropout rate (dropout) for each study. The different explanatory variables were calculated by combining three covariates in multi-variate meta-regressions.

perform a meta-analysis on the diagnostic utility of the biomarkers to predict shunt response.

\section{Limitations}

The key limitation of this study, because of the methodological weakness of the included literature, is that our meta-analysis is a pooled effect size (SMD) analysis. While this type of analysis can highlight significant differences between shunt responders and shunt nonresponders, it cannot provide information on which cutoff to choose and what the diagnostic accuracy (overall sensitivity and specificity) of each biomarker is. Future research must provide data on the true negatives, false negatives, true positives, and false positives transparently, in order to run a robust meta-analysis of diagnostic accuracy [71]. Overall, the number of studies per biomarkers was relatively low, particularly for amyloid- $\beta$ $1-42(n=3)$, which limits the validity of the meta-analysis. More robust studies are needed in this field in the future to allow for more reliable pooling of results for all biomarkers included in our meta-analysis and those that were excluded from it.

\section{Conclusion}

The lumbar CSF levels of P-Tau and T-Tau were significantly increased in shunt-non-responsive iNPH. Other CSF or venous biomarkers, including amyloid- $\beta$ 1-42, did not differentiate shunt-responsive from shunt non-responsive iNPH. More studies on Tau proteins, which not only examine differences in total levels but also sensitivity and specificity at specific cut-off levels, are needed. This would allow for a robust analysis of diagnostic efficiency and clearer guidance on the use of CSF Tau proteins for predicting shunt response in iNPH, including the best cut-off values. Similarly, further research, employing uniform shunt response criteria, must continue to examine the other CSF proteins (NFL, Albumin, VIP, Sulfatide, LRG, ECM proteins, Clusterin), as well as genotyping and proteomics analysis, to establish an adequate sample size for a meta-analysis.

Supplementary Information The online version contains supplementary material available at https://doi.org/10.1007/s00701-022-05154-5.

\section{Declarations}

Previous presentation None.

Open Access This article is licensed under a Creative Commons Attribution 4.0 International License, which permits use, sharing, adaptation, distribution and reproduction in any medium or format, as long as you give appropriate credit to the original author(s) and the source, provide a link to the Creative Commons licence, and indicate if changes were made. The images or other third party material in this article are included in the article's Creative Commons licence, unless indicated otherwise in a credit line to the material. If material is not included in the article's Creative Commons licence and your intended use is not permitted by statutory regulation or exceeds the permitted use, you will need to obtain permission directly from the copyright holder. To view a copy of this licence, visit http://creativecommons.org/licenses/by/4.0/.

\section{References}

1. Abu Hamdeh S, Virhammar J, Sehlin D, Alafuzoff I, Cesarini KG, Marklund N (2018) Brain tissue A $\beta 42$ levels are linked to shunt response in idiopathic normal pressure hydrocephalus. J Neurosurg 130(1):121-129

2. Adams RD, Fisher CM, Hakim S, Ojemann RG, Sweet WH (1965) Symptomatic occult hydrocephalus with "normal" cerebrospinal fluid pressure. A treatable syndrome. N Engl J Med 273:117-126

3. Agerskov S, Wallin M, Hellstrom P, Ziegelitz D, Wikkelso C, Tullberg M (2019) Absence of disproportionately enlarged subarachnoid space hydrocephalus, a sharp callosal angle, or other morphologic mri markers should not be used to exclude patients with idiopathic normal pressure hydrocephalus from shunt surgery. AJNR Am J Neuroradiol 40(1):74-79 
4. Ågren-Wilsson A, Lekman A, Sjöberg W, Rosengren L, Blennow K, Bergenheim AT, Malm J (2007) CSF biomarkers in the evaluation of idiopathic normal pressure hydrocephalus. Acta Neurol Scand 116(5):333-339

5. Andersson J, Rosell M, Kockum K, Lilja-Lund O, Söderström L, Laurell K (2019) Prevalence of idiopathic normal pressure hydrocephalus: A prospective, population-based study. PloS one 14(5): 0217705.

6. Andreasen N, Hesse C, Davidsson P, Minthon L, Wallin A, Winblad B, Vanderstichele H, Vanmechelen E, Blennow K (1999) Cerebrospinal fluid beta-Amyloid(1-42) in Alzheimer disease: differences between early- and late-onset Alzheimer disease and stability during the course of disease. Arch Neurol 56(6):673-680

7. Bech-Azeddine R, Høgh P, Juhler M, Gjerris F, Waldemar G (2007) Idiopathic normal-pressure hydrocephalus: clinical comorbidity correlated with cerebral biopsy findings and outcome of cerebrospinal fluid shunting. J Neurol Neurosurg Psychiatry 78(2):157-161

8. Bech RA, Waldemar G, Gjerris F, Klinken L, Juhler M (1999) Shunting effects in patients with idiopathic normal pressure hydrocephalus; correlation with cerebral and leptomeningeal biopsy findings. Acta Neurochir (Wien) 141(6):633-639

9. Bekris LM, Yu CE, Bird TD, Tsuang DW (2010) Genetics of Alzheimer disease. J Geriatr Psychiatry Neurol 23(4):213-227

10. Brean A, Eide PK (2008) Prevalence of probable idiopathic normal pressure hydrocephalus in a Norwegian population. Acta Neurol Scand 118(1):48-53

11. Cheng H, Wang M, Li JL, Cairns NJ, Han X (2013) Specific changes of sulfatide levels in individuals with pre-clinical Alzheimer's disease: an early event in disease pathogenesis. J Neurochem 127(6):733-738

12. Chen Z, Liu C, Zhang J, Relkin N, Xing Y, Li Y (2017) Cerebrospinal fluid $\mathrm{A} \beta 42$, $\mathrm{t}$-tau, and p-tau levels in the differential diagnosis of idiopathic normal-pressure hydrocephalus: a systematic review and meta-analysis. Fluids Barriers CNS 14(1):13

13. Cochrane (2021) Handbook for systematic reviews of interventions. Training.cochrane.org. https://training.cochrane.org/handb ook. Accessed September 72021

14. Covidence (2020) Covidence - Better systematic review management. Available from: https://www.covidence.org. Accessed October 12021

15. Craven CL, Baudracco I, Zetterberg H, Lunn MPT, Chapman MD, Lakdawala N, Watkins LD, Toma AK (2017) The predictive value of T-tau and AB1-42 levels in idiopathic normal pressure hydrocephalus. Acta Neurochir (Wien) 159(12):2293-2300

16. Czosnyka Z, Czosnyka M (2017) Long-term monitoring of intracranial pressure in normal pressure hydrocephalus and other CSF disorders. Acta Neurochir (Wien) 159(10):1979-1980

17. Delgado M, Ganea D (2013) Vasoactive intestinal peptide: a neuropeptide with pleiotropic immune functions. Amino Acids 45(1):25-39

18. Eckhardt M (2008) The role and metabolism of sulfatide in the nervous system. Mol Neurobiol 37(2-3):93-103

19. Eide PK, Brean A (2006) Intracranial pulse pressure amplitude levels determined during preoperative assessment of subjects with possible idiopathic normal pressure hydrocephalus. Acta Neurochir (Wien) 148(11):1151-1156

20. Eide PK (2011) Cardiac output in idiopathic normal pressure hydrocephalus: association with arterial blood pressure and intracranial pressure wave amplitudes and outcome of shunt surgery. Fluids Barriers CNS 8(1):11

21. Eide PK (2006) Intracranial pressure parameters in idiopathic normal pressure hydrocephalus patients treated with ventriculo-peritoneal shunts. Acta Neurochir (Wien) 148(1):21-29

22. Eide PK, Park EH, Madsen JR (2010) Arterial blood pressure vs intracranial pressure in normal pressure hydrocephalus. Acta Neurol Scand 122(4):262-269

23. Eide PK, Pripp AH, Ringstad G (2020) Magnetic resonance imaging biomarkers of cerebrospinal fluid tracer dynamics in idiopathic normal pressure hydrocephalus. Brain Commun 2(2):fcaa187.

24. Eide PK, Sorteberg W (2010) Diagnostic intracranial pressure monitoring and surgical management in idiopathic normal pressure hydrocephalus: a 6-year review of 214 patients. Neurosurgery 66(1):80-91

25. Eide PK, Stanisic M (2010) Cerebral microdialysis and intracranial pressure monitoring in patients with idiopathic normal-pressure hydrocephalus: association with clinical response to extended lumbar drainage and shunt surgery. J Neurosurg 112(2):414-424

26. Fleiss JL (1993) The statistical basis of meta-analysis. Stat Methods Med Res 2(2):121-145

27. Giordan E, Palandri G, Lanzino G, Murad MH, Elder BD (2018) Outcomes and complications of different surgical treatments for idiopathic normal pressure hydrocephalus: a systematic review and meta-analysis. J Neurosurg 1-13

28. Golomb J, Wisoff J, Miller DC, Boksay I, Kluger A, Weiner H, Salton J, Graves W (2000) Alzheimer's disease comorbidity in normal pressure hydrocephalus: prevalence and shunt response. J Neurol Neurosurg Psychiatry 68(6):778-781

29. Hamilton R, Patel S, Lee EB, Jackson EM, Lopinto J, Arnold SE, Clark CM, Basil A, Shaw LM, Xie SX, Grady MS, Trojanowski JQ (2010) Lack of shunt response in suspected idiopathic normal pressure hydrocephalus with Alzheimer disease pathology. Ann Neurol 68(4):535-540

30. Hartung J, Knapp G (2001) A refined method for the meta-analysis of controlled clinical trials with binary outcome. Stat Med 20(24):3875-3889

31. Hebb AO, Cusimano MD (2001) Idiopathic normal pressure hydrocephalus: a systematic review of diagnosis and outcome. Neurosurgery 49(5):1166-1186

32. Hellström P, Klinge P, Tans J, Wikkels $\emptyset$ C (2012) A new scale for assessment of severity and outcome in iNPH. Acta Neurol Scand 126(4):229-237

33. Hong YJ, Kim MJ, Jeong E, Kim JE, Hwang J, Lee JI, Lee JH, Na DL (2018) Preoperative biomarkers in patients with idiopathic normal pressure hydrocephalus showing a favorable shunt surgery outcome. J Neurol Sci 387:21-26

34. Howick J, Chalmers I, Glaziou P, Greenhalgh T, Heneghan C, Liberati A, Moschetti I, Phillips B, Thornton H, Goddard O, Hodgkinson M (2011) The Oxford 2011 Levels of Evidence. http:// www.cebm.net/index.aspx?o=5653 Accessed September 72021

35. Ishikawa M, Hashimoto M, Kuwana N, Mori E, Miyake H, Wachi A, Takeuchi T, Kazui H, Koyama H (2008) Guidelines for management of idiopathic normal pressure hydrocephalus. Neurol Med Chir (Tokyo) 48(Suppl):S1-23

36. Jaraj D, Rabiei K, Marlow T, Jensen C, Skoog I, Wikkelsø C (2014) Prevalence of idiopathic normal-pressure hydrocephalus. Neurology 82(16):1449-1454

37. Jeppsson A, Zetterberg H, Blennow K, Wikkelsø C (2013) Idiopathic normal-pressure hydrocephalus: pathophysiology and diagnosis by CSF biomarkers. Neurology 80(15):1385-1392

38. Jingami N, Asada-Utsugi M, Uemura K, Noto R, Takahashi M, Ozaki A, Kihara T, Kageyama T, Takahashi R, Shimohama S, Kinoshita A (2015) Idiopathic normal pressure hydrocephalus has a different cerebrospinal fluid biomarker profile from Alzheimer's disease. J Alzheimers Dis 45(1):109-115 
39. Johansson BB, Wikkels $\varnothing$ C, Blomstrand C, Linder L, Fahrenkrug $\mathrm{J}$ (1985) Vasoactive intestinal polypeptide in cerebrospinal fluid of patients with dementia. Nord Psykiatr Tidsskr 39(sup11):69-73

40. Klein C, Westenberger A (2012) Genetics of Parkinson's disease. Cold Spring Harb Perspect Med 2(1):a008888

41. Klinge P, Hellström P, Tans J, Wikkels $\varnothing$ C (2012) European iNPH Multicentre Study Group. One-year outcome in the European multicentre study on iNPH. Acta Neurol Scand 126(3):145-153

42. Leinonen V, Koivisto AM, Savolainen S, Rummukainen J, Tamminen JN, Tillgren T, Vainikka S, Pyykkö OT, Mölsä J, Fraunberg M, Pirttilä T, Jääskeläinen JE, Soininen H, Rinne J, Alafuzoff I (2010) Amyloid and tau proteins in cortical brain biopsy and Alzheimer's disease. Ann Neurol 68(4):446-453

43. Lei P, Ayton S, Finkelstein DI, Adlard PA, Masters CL, Bush AI (2010) Tau protein: relevance to Parkinson's disease. Int J Biochem Cell Biol 42(11):1775-1778

44. Libard S, Alafuzoff I (2019) Alzheimer's disease neuropathological change and loss of matrix/neuropil in patients with idiopathic Normal Pressure Hydrocephalus, a model of Alzheimer's disease. Acta Neuropathol Commun 7(1):98

45. Lolansen SD, Rostgaard N, Oernbo EK, Juhler M, Simonsen AH, MacAulay N (2021) Inflammatory markers in cerebrospinal fluid from patients with hydrocephalus: a systematic literature review. Dis Markers 2021:8834822

46. Luikku AJ, Hall A, Nerg O, Koivisto AM, Hiltunen M, Helisalmi S, Herukka SK, Junkkari A, Sutela A, Kojoukhova M, Korhonen V, Mattila J, Lötjönen J, Rummukainen J, Alafuzoff I, Jääskeläinen JE, Remes AM, Solomon A, Kivipelto M, Soininen H, Rauramaa T, Leinonen V (2019) Predicting development of Alzheimer's disease in patients with shunted idiopathic normal pressure hydrocephalus. J Alzheimers Dis 71(4):1233-1243

47. Malm J, Graff-Radford NR, Ishikawa M, Kristensen B, Leinonen V, Mori E, Owler BK, Tullberg M, Williams MA, Relkin NR (2013) Influence of comorbidities in idiopathic normal pressure hydrocephalus - research and clinical care. A report of the ISHCSF task force on comorbidities in INPH. Fluids Barriers CNS 10(1):22

48. Manniche C, Hejl AM, Hasselbalch SG, Simonsen AH (2019) Cerebrospinal fluid biomarkers in idiopathic normal pressure hydrocephalus versus Alzheimer's disease and subcortical ischemic vascular disease: a systematic review. J Alzheimers Dis 68(1):267-279

49. Marmarou A, Bergsneider M, Klinge P, Relkin N, Black PM (2005) The value of supplemental prognostic tests for the preoperative assessment of idiopathic normal-pressure hydrocephalus. Neurosurgery 57(3 Suppl):S17-v

50. Marmarou A, Young HF, Aygok GA, Sawauchi S, Tsuji O, Yamamoto T, Dunbar J (2005) Diagnosis and management of idiopathic normal-pressure hydrocephalus: a prospective study in 151 patients. J Neurosurg 102(6):987-997

51. Migliorati K, Panciani PP, Pertichetti M, Borroni B, Archetti S, Rozzini L, Padovani A, Terzi L, Bruscella S, Fontanella MM (2021) P-Tau as prognostic marker in long term follow up for patients with shunted iNPH. Neurol Res 43(1):78-85

52. Minta K, Jeppsson A, Brinkmalm G, Portelius E, Zetterberg H, Blennow K, Tullberg M, Andreasson U (2021) Lumbar and ventricular CSF concentrations of extracellular matrix proteins before and after shunt surgery in idiopathic normal pressure hydrocephalus. Fluids Barriers CNS 18(1):23

53. Moher D, Liberati A, Tetzlaff J, Altman DG; PRISMA Group (2009) Preferred reporting items for systematic reviews and metaanalyses: the PRISMA statement. PLoS Med 6(7):e1000097

54. Mostile G, Portaro G, Certo F, Luca A, Manna R, Terranova R, Altieri R, Nicoletti A, Barbagallo GMV, Zappia M (2021) iNPH with parkinsonism: response to lumbar CSF drainage and ventriculoperitoneal shunting. 268(4):1254-1265
55. Nadel JL, Wilkinson DA, Linzey JR, Maher CO, Kotagal V, Heth JA (2020) Thirty-day hospital readmission and surgical complication rates for shunting in normal pressure hydrocephalus: a large national database analysis. Neurosurgery 86(6):843-850

56. Nakajima M, Yamada S, Miyajima M, Ishii K, Kuriyama N, Kazui H, Kanemoto H, Suehiro T, Yoshiyama K, Kameda M, Kajimoto Y, Mase M, Murai H, Kita D, Kimura T, Samejima N, Tokuda T, Kaijima M, Akiba C, Kawamura K, Atsuchi M, Hirata Y, Matsumae M, Sasaki M, Yamashita F, Aoki S, Irie R, Miyake H, Kato $\mathrm{T}$, Mori E, Ishikawa M, Date I, Arai $\mathrm{H}$, research committee of idiopathic normal pressure hydrocephalus (2021) Guidelines for Management of Idiopathic Normal Pressure Hydrocephalus (Third Edition): endorsed by the Japanese Society of Normal Pressure Hydrocephalus. Neurol Med Chir (Tokyo) 61(2):63-97

57. Nedergaard M, Goldman SA (2020) Glymphatic failure as a final common pathway to dementia. Science 370(6512):50-56

58. Patel S, Lee EB, Xie SX, Law A, Jackson EM, Arnold SE, Clark CM, Shaw LM, Grady MS, Trojanowski JQ, Hamilton RH (2012) Phosphorylated tau/amyloid beta $1-42$ ratio in ventricular cerebrospinal fluid reflects outcome in idiopathic normal pressure hydrocephalus. Fluids Barriers CNS 9(1):7

59. Pfanner T, Henri-Bhargava A, Borchert S (2018) Cerebrospinal fluid biomarkers as predictors of shunt response in idiopathic normal pressure hydrocephalus: a systematic review. Can J Neurol Sci 45(1):3-10

60. Pyykkö OT, Helisalmi S, Koivisto AM, Mölsä JA, Rummukainen J, Nerg O, Alafuzoff I, Savolainen S, Soininen H, Jääskeläinen JE, Rinne J, Leinonen V, Hiltunen M (2012) APOE4 predicts amyloid- $\beta$ in cortical brain biopsy but not idiopathic normal pressure hydrocephalus. J Neurol Neurosurg Psychiatry 83(11):1119-1124

61. R Core Team (2020) R: A language and environment for statistical $\mathrm{R}$ foundation for statistical computing, Vienna, Austria. Accessed October 16, 2021. https://www.r-project.org Accessed October 16, 2021

62. Relkin N, Marmarou A, Klinge P, Bergsneider M, Black PM (2005) Diagnosing idiopathic normal-pressure hydrocephalus. Neurosurgery 57(3 Suppl):S4-v

63. Ringstad G, Vatnehol SAS, Eide PK (2017) Glymphatic MRI in idiopathic normal pressure hydrocephalus. Brain 140(10):2691-2705

64. Schwarzer, G (2020) \&nbsp;Package 'meta'. The Comprehensive R Archive Network https://cran.r-project.org/web/packages/ meta/meta.pdf Accessed September 72021

65. Scollato A, Terreni A, Caldini A, Salvadori B, Gallina P, Francese S, Mastrobuoni G, Pieraccini G, Moneti G, Bini L, Messeri G, Di Lorenzo N (2010) CSF proteomic analysis in patients with normal pressure hydrocephalus selected for the shunt: CSF biomarkers of response to surgical treatment. Neurol Sci 31(3):283-291

66. Serada S, Fujimoto M, Ogata A, Terabe F, Hirano T, Iijima H, Shinzaki S, Nishikawa T, Ohkawara T, Iwahori K, Ohguro N, Kishimoto T, Naka T (2010) iTRAQ-based proteomic identification of leucine-rich alpha-2 glycoprotein as a novel inflammatory biomarker in autoimmune diseases. Ann Rheum Dis 69(4):770-774

67. Shprecher D, Schwalb J, Kurlan R (2008) Normal pressure hydrocephalus: diagnosis and treatment. Curr Neurol Neurosci Rep 8(5):371-376

68. StataCorp. (2021) Stata Statistical Software: Release 17. StataCorp LLC, College Station, TX

69. Sterne JA, Hernán MA, Reeves BC, Savović J, Berkman ND, Viswanathan M, Henry D, Altman DG, Ansari MT, Boutron I, Carpenter JR, Chan AW, Churchill R, Deeks JJ, Hróbjartsson A, Kirkham J, Jüni P, Loke YK, Pigott TD, Ramsay CR, Regidor D, Rothstein HR, Sandhu L, Santaguida PL, Schünemann HJ, Shea 
B, Shrier I, Tugwell P, Turner L, Valentine JC, Waddington H, Waters E, Wells GA, Whiting PF, Higgins JP (2016) ROBINS$\mathrm{I}$ : a tool for assessing risk of bias in non-randomised studies of interventions. BMJ 355:i4919

70. Tarnaris A, Toma AK, Chapman MD, Keir G, Kitchen ND, Watkins LD (2011) Use of cerebrospinal fluid amyloid- $\beta$ and total tau protein to predict favorable surgical outcomes in patients with idiopathic normal pressure hydrocephalus. J Neurosurg 115(1):145-150

71. Thavarajasingam SG, El-Khatib M, Rea M, Russo S, Lemcke J, Al-Nusair L, Vajkoczy P (2021) Clinical predictors of shunt response in the diagnosis and treatment of idiopathic normal pressure hydrocephalus: a systematic review and meta-analysis. Acta Neurochir (Wien) 163(10):2641-2672

72. Toma AK, Papadopoulos MC, Stapleton S, Kitchen ND, Watkins LD (2013) Systematic review of the outcome of shunt surgery in idiopathic normal-pressure hydrocephalus. Acta Neurochir (Wien) 155(10):1977-1980

73. Tullberg M, Blennow K, Månsson JE, Fredman P, Tisell M, Wikkelsö C (2008) Cerebrospinal fluid markers before and after shunting in patients with secondary and idiopathic normal pressure hydrocephalus. Cerebrospinal Fluid Res 5:9
74. Vanninen A, Nakajima M, Miyajima M, Rauramaa T, Kokki M, Musialowicz T, Mäkinen PM, Herukka SK, Koivisto AM, Jääskeläinen JE, Hiltunen M, Leinonen V (2021) Elevated CSF LRG and decreased Alzheimer's disease biomarkers in idiopathic normal pressure hydrocephalus J. Clin Med 10(5):1105

75. Virhammar J, Laurell K, Cesarini KG, Larsson EM (2014) The callosal angle measured on MRI as a predictor of outcome in idiopathic normal-pressure hydrocephalus. J Neurosurg 120(1):178-184

76. Wechsler D (1981) WAIS-R : Wechsler Adult Intelligence ScaleRevised. Psychological Corporation, New York

77. Wikkelsø C, Hellstrom P, Klinge PM, Tans JT (2013) The European iNPH Multicentre Study on the predictive values of resistance to CSF outflow and the CSF Tap Test in patients with idiopathic normal pressure hydrocephalus. J Neurol Neurosurg Psychiatry 84(5):562-568

Publisher's note Springer Nature remains neutral with regard to jurisdictional claims in published maps and institutional affiliations. 